\title{
THE IMPACT OF THINKING MAPS ON ELEMENTARY STUDENTS'
}

EXPOSITORY TEXTS

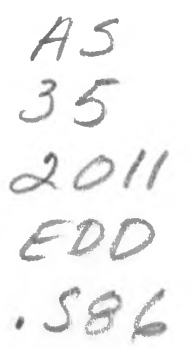

A dissertation submitted to the faculty of San Francisco State University

In partial fulfillment of The Requirements for The Degree

Doctor of Education

In

Educational Leadership

Anita Bennett Sunseri

San Francisco, California

May, 2011 
Copyright by

Anita Bennett Sunseri

2011 


\section{CERTIFICATION OF APPROVAL}

I certify that I have read The Impact of Thinking Maps on Elementary Students' Expository Texts by Anita Bennett Sunseri, and that in my opinion this work meets the criteria for approving a dissertation submitted in partial fulfillment of the requirements for the degree: Doctor of Education in Educational Leadership at San Francisco State University.
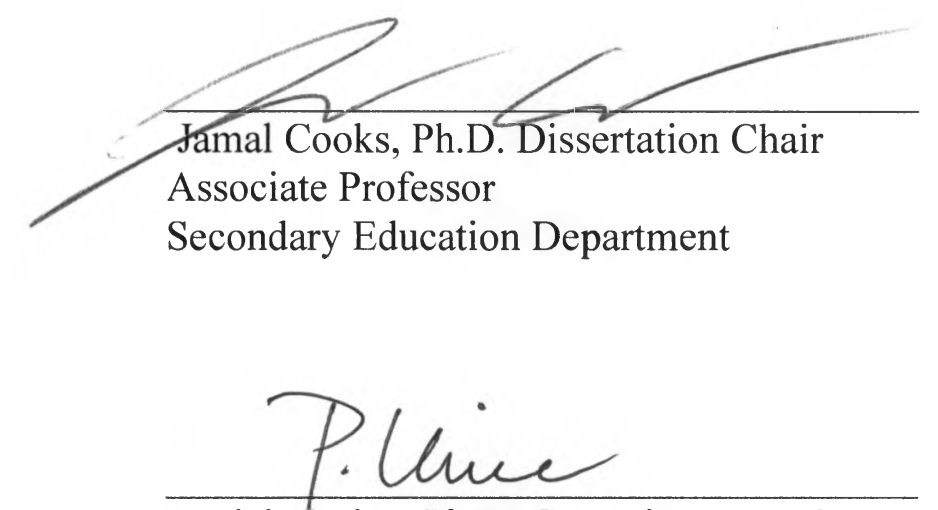

Patricia Irvine, Ph.D. Committee Member Associate Professor Associate Dean, College of Education

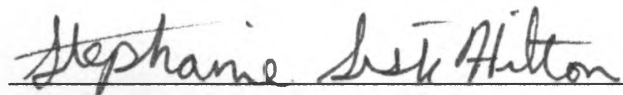

Stephanie Sisk-Hilton, Ph.D. Committee Member Assistant Professor

Elementary Education 


\title{
THE IMPACT OF THINKING MAPS' ON ELEMENTARY STUDENTS' EXPOSITORY TEXTS
}

\author{
Anita Sunseri \\ San Francisco State University \\ 2011
}

Many students struggle with structuring their writing in composing expository texts. This dissertation examined the scaffolding strategies inherent in the Thinking Maps program to see if students' compositions were more organized if they used a Thinking Map in responding to a writing prompt. The participants were 71 students in three fourth grade classes in the South Bay School District. Two of the classes were experimental in that the teachers helped students create and use Thinking Maps in addressing two writing prompts. The other class was a Control Class because Thinking Maps were not used with students. The results were Thinking Maps did not have a statistically significant impact on students' writing. However, English Language Learners (ELLs) in the Experimental Classes appeared to realize a slight benefit in using TMs compared to the non-ELL students in the Control Class. Although the evidence is weak, students appear to benefit from using Thinking Maps.

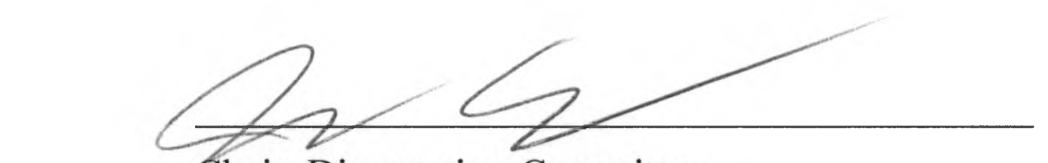

Chair, Dissertation Committee

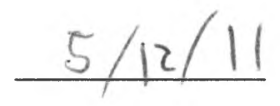

Date 


\section{ACKNOWLEDGEMENTS}

I wish to thank my husband and daughter for supporting me during the three years I participated in the doctoral program. My husband edited many of my papers. My daughter helped me format tables and other graphic representations. Thank you also to Dr. Jamal Cooks, my Dissertation Advisor who gave me such valuable guidance as I progressed through the program. Thank you to Dr. Patricia Irvine and Dr. Stephanie Sisk-Hilton for participating on my committee and providing valuable edits to my dissertation. I am very grateful to Dr. Michelle Donahue-Mendoza for mentoring me through the three year program and for editing my dissertation. Thank you to Dr. Sheldon Gen who helped me find statistical support. Thank you to Lesley Miller who helped me with statistics on my Mixed Methods paper and my Dissertation. Thanks to my district's Testing Director and Manger of External Programs who provided me with test data for the three schools and the district. Thank you to two Bilingual staff members who translated my permission forms for parents and students. Thanks to the three school principals who allowed me to use their classrooms for this study. My

sincere thanks to the three teachers who allowed me to observe their instruction and interview their students for this study. Finally, thank you to the three retired teachers who volunteered to be on the Writing Assessment Team. 


\section{TABLE OF CONTENTS}

LIST OF TABLES........................................................................... ix

LIST OF FIGURES............................................................................

LIST OF APPENDICES....................................................................

Chapter One: Purpose of the Study.............................................................1

Introduction................................................................................

Statement of the Problem.......................................................1

Description of the Problem......................................................2

Writing in California...........................................................3

Writing in the South Bay School District..............................4

Thinking Maps...................................................................6

Research Questions..........................................................

Significance.................................................................... 8

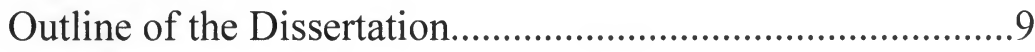

Chapter Two: Literature Review..........................................................11

Introduction............................................................................11

Methodology of the Review...............................................12

Writing as a Process.........................................................13

Writing Models to Help Struggling Students...................................16

The Self-Regulated Strategy Development (SRSD).............17

Cognitive Strategy Instruction in Writing (CSIW)...............20

Comparing the SRSD and CSIW Writing Models...25

ELLs as Struggling Writers..........................................................29

Methods to Address ELLs' Academic Challenges...............30

Visual Organizers...........................................................30

Graphic Organizers...............................................31

Concept Maps.........................................................33

Conceptual Framework for Thinking Maps..........................34

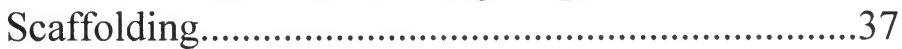

Constructivism....................................................38

Acceleration.......................................................39

Studies Using Thinking Maps.................................41 
Table of Contents - continued

Comparing Graphic Organizers and Thinking Maps $\quad 42$

Summary .............................................................43

Summary ................................................................ 43

Implications...............................................................45

Chapter Three: Methodology..................................................................47

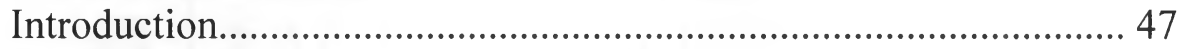

Data Sources..............................................................................48

Background....................................................................44

District Background..............................................51

Participants...........................................................52

School A.......................................................53

School B...................................................53

School C.....................................................54

Participant Observer.................................................56

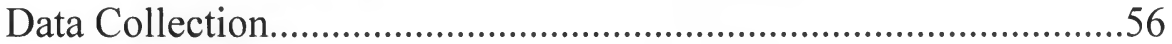

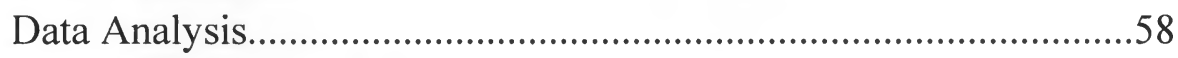

Quantitative Measures........................................................58

Qualitative Measures....................................................62

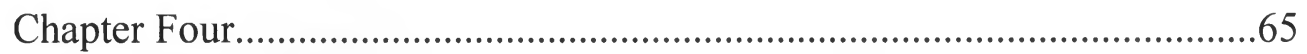

Introduction.............................................................................65

Presentation of the Quantitative Data.............................................66

Rubric Scores for Prompt \#1 ...............................................67

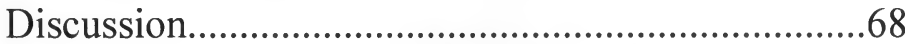

School Contexts and Pre-test Performance

Differences...............................................68

Rubric Scores for Prompt \#2...............................................71

Rubric Scores for Prompt \#3...............................................72

Rubric Categories for the Writing Prompts...........................74

Findings and Discussion....................................................78

Summary of the Quantitative Data.......................................81

Presentation of the Qualitative Data..................................................81

Finding from the Interviews.............................................83

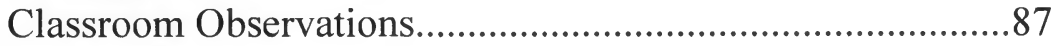

School A.............................................................88

School B...............................................................89

School C................................................................99 
Table of Contents-continued

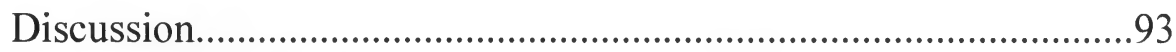

Summary of Major Findings................................................................94

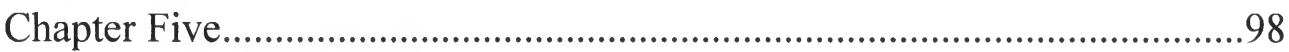

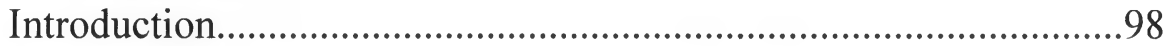

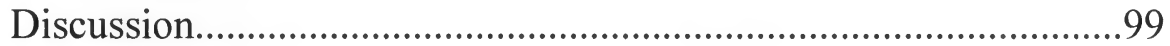

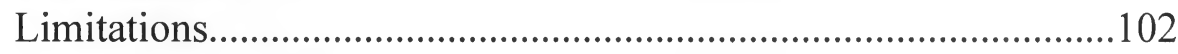

Students Grouped in Classrooms..........................................104

Comparing the Achievement of Fourth and Fifth Graders..105

Length of the Testing Period..................................................107

Variability in Writing Prompt Presentation............................107

Writing Prompt Topics...........................................................108

Writing Assessment Team's Scoring......................................108

Recommendations for Further Research.........................................109

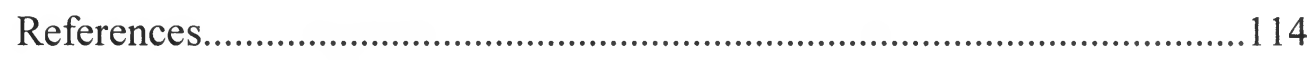

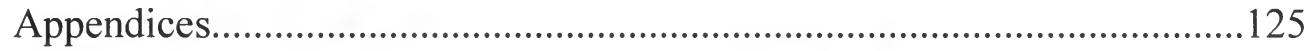


Table

\section{LIST OF TABLES}

3.1 Demographic Characteristics of School

3.2 Data Groups by School

4.1 Rubric Scores for Writing Prompt \#1 68

4.2 Writing Scores for Writing Prompt \#2 72

4.3 Rubric Scores or Writing Prompt \#3 73

4.4 Writing Prompts by Rubric Category 76

4.5 Comparison Between School C and Schools $A$ and B for the $3^{\text {rd }}$ Prompt

4.6 Comparison Between Prompt 1 and Prompt 3 for School A 79

4.7 Comparison Between Prompt 1 and 3 for All Students..................... 80

4.8 Comparison Between Prompt 1 and 2 for Non-ELL Students................ 80

6.1 Evaluators' Scores for the Pilot Papers.................................. 178

6.2 Evaluators' Scores for Writing Prompt \#1.............................. 178

6.3 Evaluators' Scores for Writing Prompt \#2............................... 179

6.4 Evaluators' Scores for Writing Prompt \#3.............................. 180 
Figure

\section{LIST OF FIGURES}

1.1 Tree Map..............................................................

\section{LIST OF APPENDICES}

Appendix

Page

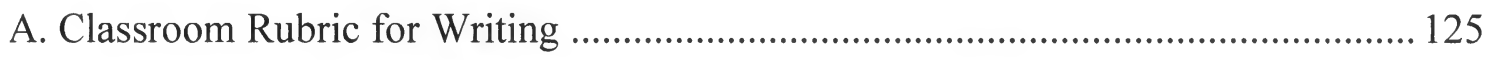

B. Writing Prompts ...................................................................................... 126

C. Interview Questions ...................................................................................... 129

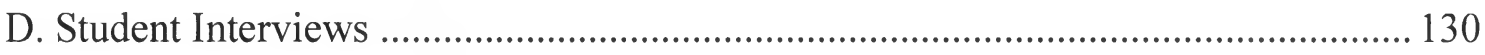

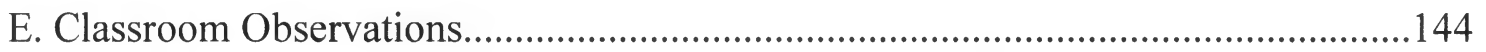

F. The Writing Assessment Team.................................................................. 174 


\section{Chapter One: Introduction}

Thinking Maps (TM) are visual organizers that have been used in various California school districts as a way to improve students' thinking and writing skills. As a principal, I learned about the program at a Ready to Learn Conference I attended in 2007. Six months later, my district had a presentation where we looked at Thinking Maps' implementation in a high poverty elementary school located in California. I looked at paragraphs written by the school's kindergarten English Language Learner

(ELL) students and was impressed by how well developed they were. Their paragraphs were half a page long and contained at least five complete sentences.

Also, I liked the fact that the Thinking Maps Program was developed for teachers in grades kindergarten through five so students could be instructed in how to build on these skills as they advanced through the grades. If students at our school were trained to write like Cahuenga's kindergartners, our students' writing skills would be well developed when they entered middle school. So in June 2008, I talked to the Staff Development Committee at my school, composed of four teachers, about participating in this program, and they agreed. Two months later, the school's teachers began the program.

\section{Statement of the Problem}

While TMs appear to provide great benefits, there is little empirical evidence on which to base this claim. Some school districts using this program maintain that their 
standardized test scores rose because TM was used in their schools. This study provides research using t-tests to determine whether the expository texts written by students using TM are more effective than those written by students using a different writing strategy. This research presents a tighter, more grounded relationship between the effectiveness of TM and its impact on students' expository compositions than previous investigations.

In the next section the problem that drives this dissertation, students struggling with writing, will be presented. Following this discussion I will describe writing programs in my school district as an example of the current status of writing programs in Bay Area elementary schools. In addition, TMs will be described as a way of helping students, especially ELLs, organize their writing.

\section{Description of the Problem}

Many elementary school students have difficulty producing grade-level work (Leinemann,Graham, Leader-Janssen \& Reid, 2006; National Commission on Writing in America's School and Colleges, 2003). The extent of this problem can be documented by the results of the latest federal writing assessment that measured $4^{\text {th }}$ grade writing skills. Three out of every four students achieved only partial mastery of the writing skills and knowledge they needed at respective grade levels. Only 1 in 100 students attained 'advanced' writing skills (National Assessment of Educational Progress, 2003). 
English Language Learners, in particular, struggle with writing because English is their second language. According to the NAEP (2003) $4^{\text {th }}$ grade writing results, while almost half of Hispanics scored one grade level below only $37 \%$ of white students did. In the South Bay School District, $51 \%$ of students are Hispanics. Of that number 38\% are ELLs. Therefore, ELLs' writing challenges represent a problem this district as well as others in California need to address.

Because the last year NAEP measured $4^{\text {th }}$ grade writing was 2002, another measure was reviewed to provide more current information about $4^{\text {th }}$ grade writing test scores. This measure was $4^{\text {th }}$ grade writing expressed as a subtest of the California Standards Tests (CSTs). According to the California Department of Education, $4^{\text {th }}$ grade writing scores rose 22 percentage points from 2003-2009 (from 39\% proficient in 2003 to $61 \%$ in 2009). Looking at this data, one can see that California students performed better than the 2002 NAEP tests with slightly more than half of the students considered proficient in writing.

\section{Writing in California}

While the NAEP and CSTs are two different assessment tests, there has been some progress in student writing since 2002. A possible reason for this growth is writing has become a subject that is taught in schools. Before the NAEP assessment in 2002, writing was not taught as a separate subject from Language Arts. Students did engage in writing but generally teachers did not present instructional models for 
students to follow. When the NAEP test results were published, the report recommended "... writing become a central focus of school reform efforts as students' educational and occupational success will be impeded if they do not learn to write well (National Commission on Writing in America's Schools and Colleges, 2003; Linemann, Graham, Leader-Janssen \& Reid, 2006). As a result, every state but Iowa established writing standards indicating that students at the elementary school level should be able to produce narratives, expository reports, letters, persuasive essays, imaginative stories and occasionally, other forms of writing (Isaacson, 2004).

In California, a major impetus for writing instruction at the elementary school level was assessing students' writing at least once a year. Up until 2010 , writing for $4^{\text {th }}$ and $7^{\text {th }}$ graders was assessed statewide as part of the California Standards Tests (CSTs). In my Bay Area school district, writing in grades 1-8, excluding grades 4 and 7 were assessed annually at the district using a writing rubric. The results were shared with the schools' teachers.

\section{Writing in the South Bay School District}

Teachers in my school district taught various genres of writing such as narrative and persuasive essays to their students in preparation for taking the writing tests. To help teachers address the writing genres and skills necessary for students to perform well as measured in each rubric area, the district distributed binders to each grade level. The binders contained writing prompts for the various genres and outlines 
teachers could use with students when they practiced various types of writing. Also, teachers used various writing programs like "Step Up to Writing" to help their students write organized text. This program presented explicit writing strategies and step-bystep guidelines along with examples to use with students. Students received guidance in various areas including writing topic sentences, writing thesis statements, organizing ideas or information, including accurate, clear, detailed support, connecting key ideas with transitions and writing conclusions (Auman, 1999).

Currently, the South Bay District is using the "Six Traits of Writing" (Culham, 2003) This is a writing program in which assessment characteristics called traits guide teachers' writing instruction. The six writing traits include the following: Ideas, Organization, Voice, Word Choice, Sentence Fluency and Conventions. According to Culham (2003), teaching students to practice and internalize the traits helps them gain control and confidence in their own writing. So the purpose of the program is helping students become better writers by helping them evaluate and practice writing using these characteristics.

However, I found at my school that even with these writing programs students were not getting ongoing, systematic instruction to organize their paragraphs especially at the upper elementary grades. As a result, many students had trouble writing wellorganized compositions. One reason for students' writing problems is that teachers must spend most of their instructional day teaching reading and math. While writing is 
no longer assessed statewide, students are tested annually in reading and math. The results of these tests could have dire consequences for those schools whose students are not meeting proficiency targets in these academic subjects. As a result, while teachers spend at least three and a half hours a day in Reading and Math, writing may not be getting the systematic attention it deserves.

Also, some teachers may not feel comfortable about teaching writing because they need to design a program that is coordinated with the curriculum their students are studying. Culham (2003) maintained that while teachers want one source like a kit or a curriculum guide that will meet the writing needs of students, they quickly discover this is not possible. As a result, some teachers do not offer an organized and effective writing program in the classroom.

\section{Thinking Maps}

The Thinking Maps Program represents a way to help students write wellorganized expository compositions. The program was created by David Hyerle in 1990. He based it on the belief that people's ability to learn visually is greater than our other senses (Hyerle \& Yeager, 2007). Like concept maps and graphic organizers, the nature of this program is constructivist in that students can make meaning of an abstract concept by reducing it to paper (Hyerle, 2004). It represents a common visual language where students can focus on critical thinking and use it as a scaffold to improve writing 
skills, among other proficiencies (personal lecture notes, Ready to Learn Conference, Anaheim, October, 2007).

There are eight kinds of Thinking Maps, each concerned with a specific skill such as showing cause and effect or comparing and contrasting. An example of the Tree Map appears in Figure 1.1 below. The top of the map is a horizontal line where the title is written. Underneath this line are vertical lines that radiate from the top line. Each vertical line contains details about the topic sentence. The ideas radiating from each vertical line would form a paragraph when the student begins writing.

Figure 1.

The Tree Map

\begin{tabular}{|c|c|c|}
\hline \multicolumn{3}{|c|}{ Main Idea } \\
\hline & 1 & \\
\hline 1 & 1 & I \\
\hline Supporting & Supporting & Supporting \\
\hline Idea & Idea & Idea \\
\hline 1 & 1 & 1 \\
\hline detail & detail & detail \\
\hline & & \\
\hline
\end{tabular}

\section{Research Questions}


There are two research questions. One, what is the impact of using Thinking Maps on elementary students' expository writing, especially text written by ELLs, as compared to writing where a Thinking Map is not used? Two, how do students believe that Thinking Maps impact their writing.?

I am using a causal comparative design for this study. This type of study looks at the effects of a treatment that has already been given to a group of participants and compares it to those not getting the treatment (Fraenkel \& Wallen, 2009). For the current study, the treatment is Thinking Maps. I will be comparing a $4^{\text {th }}$ grade and a $4^{\text {th }} / 5^{\text {th }}$ grade combination that are using Thinking Maps to structure their writing versus a $4^{\text {th }} / 5^{\text {th }}$ grade combination class in which the teacher is using a different writing strategy with students.

\section{Significance}

According to Short (2000), students, especially ELLs, need three specific skills to be successful in school. They include using academic English, understanding concepts in content area subjects such as social studies and science and producing required papers and projects. This triad represents gatekeeper skills that students should possess to attain their academic potential as represented by successfully completing college. Based on this information, it is important to study those programs that will help students, especially ELLs, attain those skills. Unfortunately, very few studies have examined practices helping ELLs procure these proficiencies. This study will contribute by exploring ways to help ELLs be academically successful. It will 
investigate whether a visual organizer like Thinking Maps can help students, especially ELLs, understand how concepts in the content areas relate to each other and use academic language to explain this relationship in a well-organized expository paragraph. In particular, this study will look at how translating a Thinking Map into a writing outline will organize students' expository paragraphs. Thus, the effectiveness of using Thinking Maps as an outline and paragraph organizer will be measured by the quality of students' expository compositions when they use Thinking Maps versus those compositions written by students who do not use Thinking Maps.

This study's results will contribute more information to the literature about how teachers can accelerate ELLs' learning so they can achieve their academic potential. If the results indicate that the Thinking Maps Program is more effective than

other writing strategies at organizing expository paragraphs, especially with ELLs, then this program could be used more extensively especially with this student population. This study may also engender more investigation about how visual organizers can help students, especially ELLs, comprehend concepts and demonstrate what they know in writing.

\section{Outline of the Dissertation}

In Chapter 2, the need for writing models to help struggling students will be explored. Studies of these earlier models examined the effectiveness of their methods on the writing of students with various problems including Learning 
Disabilities and ADHD, among other learning challenges. As struggling writers, the academic challenges of ELL students will be discussed as well as the way visual organizers can assist them to improve their writing.

In Chapter 3, the methodology for the study will be presented. The information in this chapter includes who will be participating and the data sources that will be used. This dissertation is a mixed method study containing both quantitative and qualitative sources. The quantitative sources are rubric scores derived from assessing three compositions written by students in three classes. The qualitative sources will be video interviews of six students and the researcher's classroom observations.

In Chapter 4, the data from the quantitative and qualitative sources will be analyzed. The findings will be synthesized and the researcher will interpret how these findings relate to the research questions posed by this study.

In Chapters 5 and 6, the implications of the study's findings will be discussed along with an examination about how these conclusions may affect teaching and learning. Also recommendations for further study will be presented. 


\section{Chapter Two: The Literature Review}

\section{Introduction}

As stated in Chapter 1, many students have difficulty producing grade-level work in writing at the elementary school level. This assertion was documented by the results of the NAEP study in 2002 of fourth grade writing. It showed that only a quarter of the students tested were proficient in writing (NAEP, 2003).

The goal of this literature review is to examine several instructional techniques that have been empirically studied with different groups of students who have been identified as struggling with writing. They include students who are Learning Disabled, academically challenged, English Language Learners (ELLS) and those who are regular education students--meaning those who have no identified special learning needs.

Knowing the results of these studies could help determine which instructional techniques are the most effective with certain groups of students. Thus, these strategies have the potential of improving student learning for those students who have difficulty in writing.

One approach, Thinking Maps, shows particular promise especially with ELLs.. It is based on students understanding concepts by mapping them on paper. Students can use these maps as scaffolds to break down the meaning of concepts and create outlines that will structure their compositions. The power of this approach lies in students being 
able construct their own meaning by representing the relationship among concepts on paper.

\section{Methodology of the Review}

The focus of inquiry for this study is looking at the various writing strategies that help struggling students write expository essays more effectively. Specifically, the effectiveness of using writing models and visual organizers such as graphic organizers and Thinking Maps with struggling writers is investigated. The sources for this study included quantitative studies that determined whether a particular writing program helped students write more effectively. These studies were found primarily in peerreviewed studies and books. The key words used to search the literature were: (a) thinking maps; (b) concept maps; (c) graphic organizers; (d) expository writing; (e) struggling writers; (f) ELLs' writing challenges; and (g) writing models. The following electronic databases were searched: ProQuest Educational Journals, ERIC, Google Scholar and Academic Search Premier. A writing source was used if it presented a study that investigated the use of a writing model on students' expository writing at the elementary school level. The key terms that emerged from the literature review were: (a) writing as a process-writing seen as a series of steps the writer completes; (b) writing models-an outline or schema presented to students prior to their composing that helps them organize their writing and structure their thoughts; (c) English Language Learners (ELLs)-students in the beginning stages of learning English as a second 
language; (d) expository writing-writing that explains, describes and informs; (e) scaffolding- reading selections' major concepts broken down to be understood more easily; (f) visual organizers-instructional strategies like graphic organizers and Thinking Maps that students can use to scaffold main ideas and details in preparation for writing. This chapter is organized into five sections. In the first section, the theoretical framework for writing instruction and the writing process are presented. In the second, writing models are discussed as an early attempt to help struggling students write more effectively. In the third, the challenges ELLs face in acquiring academic reading comprehension and writing skills and the strategies used to help these students are examined. In the fourth, the benefits of using graphic organizers and concept maps to help students write more effectively are discussed. In the fifth section, the way Thinking Maps fit in as a way to help students structure their paragraphs is presented. The goal is to discuss a variety of writing instructional strategies and their effectiveness with certain groups of students. Finally, an overall summary and assessment of the literature are presented.

\section{Writing as a Process}

Designing instructional strategies to help struggling students is based on viewing writing as a process. Hayes and Flowers (1981) visualized the heart of this process as generating ideas for writing. Their theory is based on cognitively oriented research and 
focused on the interconnections among thinking, learning and writing. Their cognitive processing theory rests on four key points:

(1.) The process of writing is best understood as a set of distinctive thinking processes which writers orchestrate or organize during the act of composing.

(2). These processes have a hierarchal, highly embedded organization in which any given process can be embedded within any other.

(3.) The act of composing itself is a goal-directed thinking process, guided by the writer's own growing network of goals; and (4.)Writers create their own goals in two key ways: by generating both high level goals and supporting sub-goals which embody the writer's developing sense of purpose, and then, at times, by changing major goals or even establishing entirely new ones based on what has been learned in the act of writing ( p. 366).

Thus, writing instruction based on the authors' theories focused on a clear understanding of the organization of cognitive processes underlying the act of writing. The performance of writing contained three elements: planning, translating and reviewing. For example, a writer would come up with an idea. Then from planning the writing, an outline would be formed. Paragraphs would then be generated from the outline. In the final step, paragraphs would be reviewed and necessary revisions made. 
Using a Thinking Map reflects the writing process because students would create a map to delineate the characteristics of a concept or its relationship to other concepts. Students would then create a writing outline from this map and use it to organize their compositions.

Scardamalia and Bereiter (1986) extend the writing process theory of Hayes and Flowers (1981) by suggesting that students could learn how to write effective compositions if their teachers modeled the steps of the writing process. In translating the ideas of Scardamalia and Bereiter into classroom practice, the students would write the paragraphs about their chosen topic and then revise what they wrote. In Hillocks's (1984) meta-analysis of effective writing models, the writing process model in which the teacher modeled the writing process for students was judged more effective in improving students' writing than when teachers only talked about how paragraphs should be written without showing them how to write. In the Thinking Maps model., the teacher models the writing process by demonstrating a Thinking Map with students and shows how they can take the information from the map to form a writing outline.

Currently, the writing process method is still being used in classrooms. However, certain instructional strategies have been recommended to help students write effectively (Bromley, 2007). One recommendation is that writing and instruction in the conventions of grammar and spelling should be taught simultaneously (Bromley,2007; 
Peterson, 2000). In that way, using terms like "purpose", "noun", "verb" and "adjective" with students as they write give them a common vocabulary for discussing and improving their writing (Bromley, 2007; Peterson, 2000). ). Bromley (2007) also recommends the teacher's creating a community of writers. In that context, students help each other write collaboratively. Further, students can learn from viewing concrete writing passages presented to them on the board. Teachers can present samples of their own writing as these concrete examples and talk about why they made certain word choices. Teachers can also ask their students to suggest possible changes. In that way, students can learn from real-life examples of writing. Also, Gersten and Baker (2001) stated that, other than the teacher's modeling the writing process, teachers' conferencing with individual students about their writing helped students improve. Another method for helping students write more effectively is teaching text structure to students. That is, the structure for writing paragraphs is modeled for students, and they work on translating it into their own compositions (Isaacson, 2004).

\section{Summary}

The writing process as theorized by Hayes and Flowers (1981) has been presented as a series of steps students need to follow to write an effective composition. These steps include coming up with an idea, creating a writing outline that fleshes out that idea, translating the outline into a composition and revising the written product. Several authors, including Scardamalia and Bereiter (1986) suggest that students can 
write effective compositions if their teachers explain the steps and model it for them. Currently, Bromley (2007) and Peterson (2000) concur that teaching the writing process to students is an effective instructional technique along with creating a community of writers in the classroom in which students can collaborate on writing tasks. These studies underlie using Thinking Maps as a writing strategy because teachers guide students in concretizing their understanding of concepts by creating a map that explains the elements of the concepts. When teachers help students create a writing outline from the map that they can use to develop a composition, they are modeling the writing process theories of Hayes and Flowers (1981).

\section{Writing Models to Help Struggling Students}

A group of students who have been identified as struggling with writing are those with learning disabilities and other academic challenges (Gersten \& Baker, 2001). These students struggled with writing for several reasons identified in the literature. For example, their papers lacked planning and organization (Hillocks, 1984). They have problems monitoring their own writing especially when they wrote expository compositions ( Englert, Raphael \& Anderson, 1992). Also, students have difficulty knowing how to adapt their writing to the assignment being presented (Englert, Zhao, Dunsmore, Collings \& Wolpers, 2007). In addressing these students' needs, writing models have been developed to help them improve their writing. A writing model is an outline or schema that is presented to students prior to their composing that helps them 
organize their writing and structure their thoughts. The following presents writing models developed by two groups of researchers: Graham and Harris (1989,2005a) and Englert and Rafael (1992).

\section{The Self-Regulated Strategy Development (SRSD).}

In 1989, Graham and Harris introduced the Self-Regulated Strategy Development (SRSD) model of writing instruction.. SRSD involves explicitly teaching students strategies for completing specific writing assignments. These strategies include knowing the specific attributes of a writing style, such as how to compose an expository paragraph. Students are also taught self-regulatory practices like goalsetting and self-monitoring to motivate them and keep them on track as they are writing. The emphasis of this instruction is showing students how to adapt a writing strategy to a particular writing task. (Graham \& Harris, 1989).

This process (SRSD) devised by Graham and Harris (1989) was used in several quantitative method studies involving students with special learning needs. (Leinemann, Graham, Leader-Janssen \& Reid, 2006; Lane, Harris, Graham, Weisenbach, Brindle and Murphy, (2008); Reid and Leinemann (2006); Goddard and Sendi (2008); Torrance, Fidalgo and Garcia ()2007) Means and standard deviation were used that measured students' writing scores before and after they were taught the SRSD process. The following studies showed that the use of SRSD process improved students' stories in both length and quality of writing. 
In a study by Leinemann et al. (2006), the participants were ten second grade students identified as being at risk of writing failure. The authors used the same elements in the SRSD instruction as those mentioned by Graham and Harris including strategies for planning and writing and the knowledge needed to apply these strategies. The authors found that the quality of these students' writing increased at least $100 \%$ from their baseline scores. They concluded that these findings indicate that early intervention with specific instructional techniques like the SRSD model could have a positive impact on students who had difficulty writing. The study might raise several questions. One, how much time was spent with the students on the process? Two, how could one determine whether the SRSD Program or intense work with students affected the difference in the writing scores before and after they participated in the program?

Lane, Harris, Graham, Weisenbach, Brindle and Murphy (2008) studied six second graders identified as having emotional problems, and used the SRSD model. These students' ages ranged from 7.5 to 8.3 years of age. These students' IQs were measured. as part of a screening process to identify students with behavioral problems. The students' writing was evaluated before and after the instructional treatment. In measuring the quality of writing, the mean for the pre-test was 2.5 . After the students were taught SRSD techniques the mean was 6.5. The authors maintained the data showed a distinct improvement in the quality of the students' stories. One thing I would question about this study is the large degree of improvement between the pre-test and 
post-test. One reason for this difference may be that the pre-test results were extremely low to be begin with. That may have occurred because the students may not have been getting the attention they needed to learn effectively before they participated in this study.

Also, Reid and Leinemann (2006) used this model with three children. One student was in third grade and two were in fourth grade. All were identified as having Attention Deficit Hyperactivity Disorder (ADHD). Using SRSD strategies, these authors helped the students plan and write a story. The students were also assisted in using strategies to help them stay focused on writing. Before the SRSD strategies were used, students' stories were evaluated. The mean score was 1.5 on a rubric where 4.0 was the highest score. After the treatment, the mean score of the students' stories was 2.8. The authors concluded that SRSD helped students with ADHD improve their story writing.

In a related study by Goddard \& Sendi, (2008), four fourth grade students with LD were taught self-monitoring strategies in writing that followed the SRSD Program. The major finding of this study was the quality of the students' writing improved for three of the four participants. The pre-test scores ranged from 4.5 to 6.5 from a total of 15 points. After the students participated in the SRSD program, the scores ranged from 8.0 to 8.5 . Also, quantitative measures showed students' compositions were longer. 
SRSD emphasized teaching students the writing process so they could monitor their progress as they wrote. The SRSD writing model was used almost exclusively with students who were struggling or who had identified learning problems. As the data showed, students' writing improved when they were taught to use this process. Equally important, students were shown strategies to monitor their writing process on their own.

However, the SRSD studies have several shortcomings. First, they tend to support very small numbers of students involved in this intervention--from 3-10 students. None of the studies had control groups and were not able to separate the amount of individual attention a student was given from the SRSD process. In other words, it was not possible to isolate any of the gains that students made to the SRSD method. Second, those who presented the program were highly trained: that engenders a concern about how much training teachers would need to implement the program successfully with their students.

\section{Cognitive Strategy Instruction in Writing (CSIW).}

CSIW was another writing program designed to help students write effectively. In presenting this program to students, teachers gave a writing prompt to their students with a writing outline the students would complete in preparation for writing. Teachers would then respond to the prompt themselves and use their writing as a model to share with students. Then the teacher would help the students complete the writing outline and guide them through the writing process. 
The studies investigating the use of CSIW used t-tests to determine whether writing improved when students were taught this method versus those were not taught this method. The results of these studies showed that students who were taught CSIW wrote more effectively because they were taught how to organize their paragraphs using writing outlines.

Englert, Stewart and Hiebert (1988) studied 62 third graders and 61 sixth graders. They measured the students' abilities to complete unfinished paragraphs by generating main ideas and/or specific details for three different scenarios that the researchers gave them. They found that if students knew how a written passage was structured and organized, they were able to use that knowledge to write well-organized compositions.

Englert, Raphael and Anderson (1992) studied 63 students in $4^{\text {th }}$ and $5^{\text {th }}$ grades. Half were Learning Disabled (LD) students and half non-LD students. Twenty students were in the control group with ten LD and ten non-LD students. Thirty-two students were in the experimental group and, like the control group, were evenly divided between LD and non-LD students. The experimental group was taught the CSIW program by a trained researcher while a teacher taught the control group not using this method. This was a mixed method study. Both groups were interviewed about what constituted a good paragraph. Their knowledge about paragraphs was also measured by t-tests comparing the responses to the two groups. The results were that 
students in the experimental group were much more knowledgeable about the writing process and using text structure. While the authors stated that the quality of the students' writing was measured, no results were presented in the study.

Another study by Englert, Raphael, Anderson, Anthony and Stevens (1991) used a think sheet with students writing expository paragraphs. The study participants were 183 fourth and fifth graders from twelve lower-income schools that represented a variety of ethnic groups. Both the control and experimental groups contained low and high-achieving students and those identified as learning disabled. The experimental group used CSIW in paragraph writing. In the control group, the teacher used the district's writing curriculum that did not contain CSIW. The authors used t-tests to determine differences between the experimental and control groups in writing paragraphs involving compare/contrast and other types of expository paragraph types. The pre-test scores for the experimental group ranged from .83 to 1.11 while those for the control group ranged from .95 to 1.48 . The post-test scores for the experimental group ranged from 1.27 to 2.06 while those for the control group were 1.10 to 1.85 . The data show that the differences in the scores between the two groups were significant.

Finally, a study by Torrance, Fidalgo and Garcia (2007) used CSIW with sixth grade students who attended two Spanish-language private schools in the United States. The students participated in a ten session, classroom-based CSIW program that was 
designed to teach the students writing skills such as preplanning, and revising.. As a result if this treatment, the authors found that the quality of students' paragraphs was much greater because the students were more able to regulate their writing and apply writing strategies effectively as a result of using the CSIW program.

There are gaps in the CSIW studies. One is that the method of conducting the studies varied. Some used experimental and control groups while others used small groups of students. Thus, the results could not be generalized regarding the effects of CSIW on student writing. Also, the studied populations varied with some studies including LD and non-LD students. Others used only LD students like those in the SRSD research. Consequently, the results of these studies proved to be inconsistent.

Two studies investigated using SRSD and CSIW with students. The authors of these studies found that students benefitted from being taught both programs. Students were able to use text structure as presented by CSIW to organize their writing and in using SRSD, they were able to monitor their own writing progress.

Guzel-Ozmen (2009) examined the possibility of using the same two programs (CSIW and SRSD) with mildly retarded students on an individualized basis. Four mildly retarded adolescent students were taught writing and revising skills with a modified version of CSIW which contained elements of the SRSD program. The effectiveness of the two programs was determined by examining the students' skills in generating problem-solving compositions using a multiple probe design. The study's 
findings indicated that students' texts improved in quality, coherence, text coherence and text length. The author's conclusion was these two programs could be successfully implemented with students who had identified cognitive challenges like mental retardation.

A study by Deatline-Buchanan and Jitendra (2006) looked at the impact of SRSD and CSIW on the way five $4^{\text {th }}$ grade LD students wrote an argumentative essay. The authors used a planning sheet that helped anchor the students' arguments and helped them self-regulate their writing processes as defined by Graham and Harris (1989). In this quantitative study, the authors evaluated student work based on rubric scores and other measures such as number of words in the composition on pre and posttests. The results were mixed. There was great improvement in the number of words written. For example, while the pre-test mean for the number of words was 39.20 , the post-test mean was 141.60 words. However, only three of the five students made gains in clarity and cogency.

Englert (Englert, Wu \& Zhao, 2005; Englert, Xhao, Dunsmore, Collings \& Wolbers, 2007). published two additional studies regarding writing. Both involved using a computer program, Technology-Enhanced Learning Environment (TELE-Web) to help students in fourth and fifth grades to write. The purpose of these studies was determining whether a computer program could help the students organize their paragraphs by providing assistance in creating a writing outline. In both studies a 
statistical measure was used to determine if students using the computer program produced better quality paragraphs than those who were taught the conventional writing curriculum. The results of both studies were that students using TELE-Web wrote better-organized paragraphs because they used the outlining assistance provided by the computer program

\section{Comparing the SRSD and CSIW writing models.}

Since the SRSD and CSIW Writing Models are the two major writing models helping students write more effectively, it might be helpful to define the differences between the two models in how they help different groups of students struggling with writing. The first difference is that while SRSD emphasizes teaching students the writing process so they could monitor their progress as they wrote, CSIW relies more on the interaction between the teacher and students. The program entails teachers modeling the writing process with their students and giving them think sheets as outlines to structure their expository writing. Another difference is the SRSD writing model is used almost exclusively with students who are struggling or have identified learning problems. The CSIW model is used with larger groups of students who were LD and non-LD students. Thus, while the SRSD strategies target students with identified learning problems (LD,ADHD), the CSIW techniques could be used with a student whether he/she is identified as having special learning needs. . Based on these studies' results, Gersten and Baker (2001) and Gersten, Baker and Graham (2003) offer several suggestions to help 
students write effectively. They include (a) teaching the writing process explicitly and (b) giving feedback to students in a systematic way.

Another study looked at the effects of a different writing model, the Demand Writing Instruction Model (DWIM), with fifth grade students. The study's results are significant because a state writing test was used to measure DWIM's effectiveness as a writing model. Bui, Schumaker and Desler (2006) examine whether DWIM would improve the writing of $L D$ and non-LD students as measured by their scores on a fifth grade state-wide writing assessment test. This writing program, DWIM, is similar to the CSIW program because students were given a planning sheet that provided them with an outline when they wrote their paragraphs. This study is important, because unlike those previously cited, it uses a standardized measure, a statewide writing test, that compared the students' writing with that of other fifth graders in the state of California. This study's results may have more credibility because the compositions of students receiving the experimental treatment were being compared not only to the writing of the control group students but that of other fifth graders in the state. The other empirical studies only compared the results of the students participating in those investigations using assessments administered to individual students. The authors found that although the average of the writing scores on the fifth grade state writing test were higher for students who were taught DWIM as compared to those in the control group, the differences were not statistically significant. 
The literature review has highlighted the impact of using writing models like SRSD, CISW and DWIM with students who had various learning problems and those who did not. The Thinking Maps Program has certain similarities to the CSIW and DWIM models in that both of these programs feature giving students a writing outline that they can use to write compositions. When students use a Thinking Map, they create a writing outline from that map to use in structuring their text.

The writing process theory that Hayes and Flowers (1982) and Scardamalia and Bereiter (1986) propose is with students who generate writing ideas and write paragraphs using a framework or structure. These ideas have provided the foundation for the writing models that have been presented. Much of the work done in using this process with struggling writers has been advanced by Graham and Harris $(1989,2005 a)$ and Englert and Rafael (1992) with generally successful results. Also, another writing model, DWIM, is discussed that represents an adaptation of the SRSD and CSIW models. However, there appears to be some disadvantages in using these approaches. The instruction is very intense and is often focused on working with small groups of students. Also, those who present the program to students are highly trained. This engenders the concern of how much training teachers would need to implement the program successfully with students. Finally, not only do these studies represent an implementation of the writing process theory, they also answer several questions posed by the literature review. Specifically, what writing models have been used in the past? 
And, which student populations participated in these writing programs and what were the results?

Earlier models focused on helping students with learning disabilities who struggle with writing. Their writing difficulties stem from their inability to perform the cognitive tasks associated with writing like being able to choose a topic and write about it in an organized way. The writing models include SRSD and CSIW that researchers used to teach students text structure so they could form their compositions based on the assignment's writing requirements (Englert, Wu \& Zhao, 2005; Englert et al., 1991).

Like many Learning Disabled (LD) students, many English Language Learners (ELLS) struggle with writing. The challenges of ELLs are different from those faced by LD students and others who are under-achieving. While LD students face challenges with structuring their writing, ELLs face language difficulties when they write compositions in their second language that is English. Thus, these students need to learn academic English by being able to understand and write about concepts in their content area subjects like social studies and science.

\section{ELLS as Struggling Writers}

English Language Learners (ELLs) have particular struggles with writing because of their challenges with reading and writing English fluently. They do not have the same literacy skills in English as their classmates whose first language is English. (Echevarria, Short \& Powers, 2006) Without oral and written proficiency in English, 
these students are not able to show what they know in content subjects such as mathematics and science (Echevarria, Short \& Powers, 2006; Banks, Cochran-Smith, Moll, Richert, LePage, Darling-Hammond, Duffy \& McDonald, 2005). As a result, ELLs struggle with writing because of their challenges in reading and writing fluently. Viewing ELLs as struggling writers was buttressed by national standardized test results. According to the latest NAEP results, there was a significant gap in fourth grades writing scores between White and Hispanic students (NAEP, 2003). For example, while only $10 \%$ of White students were two years below grade level, $23 \%$ of Hispanics were. Further, almost half of Hispanic students scored one year below grade level as compared with $36 \%$ of White students (NAEP,2003). While ELLs form a subgroup within the Hispanic student population, those students with beginning levels of English fluency usually did not take the test. Beginning in 1998, this group of students was given accommodations when they took the test. The accommodations included students' using a glossary that would translate English words into Spanish and vice versa without defining the words. (Grigg, Daane, Jin \& Campbell, 2003). The result was more ELLs were tested but were generally below grade level in writing.

\section{Methods to Address ELLs' academic challenges.}

Various authors have recommended approaches like scaffolding to help ELLs learn English and help them write academically (Echevarria, Short \& Powers, 2006; August. Beck, Calderon, Francis, Lesaux, Shanahan, Erickson \& Siegel, 2008; Novak \& 
Canas, 2008; Rosenshine, 1997) The Education Alliance: Teaching Diverse Learners, 2006; Cobb, 2004). This method takes a reading selection's major concepts and breaks them down so students are able to understand them more easily. These scaffolds then become schema or skeleton outlines students can use in comprehending written passages and seeing the relationships among the vocabulary words in the selections.

\section{Visual organizers.}

Because many of the strategies developed to help ELLs learn English involve visual presentations like scaffolding reading selections, visual organizers offer a means of helping ELLs in two ways. One, visual organizers can help ELLs learn important concepts by showing their relationship on paper. Two, these organizers, particularly TMs, can help ELLs transfer the conceptual relationship created on paper to outlines they can use to structure paragraphs that discuss the relationship among the concepts (Echevarria, Short \& Powers, 2006; August et, al., 2008; Novak \& Canas, 2008; Jiane \& Grabe, 2007; Cobb, 2004)

\section{Graphic Organizers.}

Graphic organizers represent a way of presenting the relationship among key terms on paper. These images, originally known as structured overviews, look like tree diagrams (Moore \& Readence, 1984). It is based on Ausabel's (1963) theory of meaningful reception. Ausabel believed that new meanings are acquired when they are related to previous learning. Further, this learning is enhanced when the new 
information is clearly and concisely organized. He suggested teachers organize this information graphically to facilitate student's acquisition of this knowledge. According to Stull and Mayer (2007), graphic organizers include hierarchies, matrices, outlines and lists. The elements in a graphic organizer contain words or word groups. Relationships among elements are shown by the spatial arrangements of words on the page. Finally, the graphic organizer represents the text's conceptual organization.

The benefits of using graphic organizers with students as a whole have been documented in several studies. Simmons, Griffin and Kameenui (1988) studied the use of this strategy with sixth graders who were studying science. The total number of participants was forty-nine. They were divided into three groups. One experimental group was given a teacher-made graphic organizer before the science lesson was read. The second experimental group received the graphic organizer after the selection was read. The third group was given the conventional instruction in reading the selection. The authors used quantitative measures to assess the pre and post-test results of the students. A post-test was given to the students eleven days after the graphic organizer had been presented to them. The means on the test of the group getting the pre-reading graphic organizer was 15.86 as compared with 11.00 for the post-reading graphic organizer. The authors considered the results statistically significant for the graphic organizer groups because the data demonstrated that a pre-reading graphic organizer helped students recall reading selections more effectively than a post-reading graphic 
organizer. These results are important because they buttress the idea that students will remember knowledge if its key points are presented before they are taught. In that way, graphic organizers set the stage for learning by letting the students know the components of what they will be learning.

In a related study by Griffin, Malone and Kameenui (1995) the authors investigated the use of graphic organizers and explicit instruction with students using social studies texts. The participants were forty-seven fifth grade students who were placed into one of five groups. The four experimental groups received a mixture of being taught a graphic organizer coupled with either explicit or implicit instruction. The fifth group was taught the curriculum in a conventional way. The authors found the group who received both graphic organizer and explicit instruction did the best in comprehension and recall measures.

These studies' results are buttressed by a literature review of graphic organizers presented by Stull and Mayer (2007). They stated that various investigations posit that students benefit from using graphic organizers because this strategy breaks down highlevel knowledge and concepts in a way students can understand. Also, when learners use this strategy, the focus is on integrated ideas rather than isolated facts $(R . H$. Hall,1994; Hall \& Saling, 1999; O’Donnell et al. 2002 cited in Stull and Mayer (2007).

\section{Concept Maps.}

According to Novak and Canas (2006): 
Concept maps are graphical tools for organizing and representing knowledge. They include concepts, usually enclosed in circles or boxes of some type, and relationships between concepts indicated by a connecting line linking two concepts. Words on the line, referred to as linking words or linking phrases, specify the relationship between the two concepts (p. 1).

Chang, Sung and Chen (2002) maintain that concept maps are a type of graphic organizer. Further, they state that concept maps are usually used to map scientific concepts but they are used less often in comprehending reading selections. An example of using concept maps with students to help them learn scientific concepts is a study by Stoddart (2006) who used concept maps with ELL students in science. Participants included two hundred students in grades two through five. These students were attending a summer program and were children of migrant workers. Their English language fluency ranged from beginning to intermediate. A teacher and the author taught the students how to create these maps. They were scored by two trained researchers in the areas of scientific accuracy and depth of explanation. Using graphs, the author found that ELL students were able to show their understanding of scientific concepts. Also their knowledge of science vocabulary increased from $14 \%$ to $53 \%$ in the pre and post assessments. The author suggested that students were able to learn both science content and the academic language of science by using concept maps (Stoddard, 2006). This is an important study because it shows how a visual organizer 
such as a concept map can help ELLs learn content area concepts and vocabulary. Being able to learn content area knowledge and demonstrate that learning will help these students succeed academically (Short, 2002)

\section{Conceptual framework for Thinking Maps.}

As mentioned previously, TM is a visual organizer teachers can use to help students think and write more effectively. It represents a visual language students can use to focus on critical thinking and use as a scaffold to improve expository writing skills, among other proficiencies. Advocates of TM believe a major advantage in using these maps is the student's ability to translate the information from the map to writing a paragraph. (Hyerle, 2004; Yeager, 2004; Jackson, 2004). In that way, any of the Thinking Maps can be seen as a writing outline the students can flesh out into paragraphs.

The idea of using Thinking Maps to help students, especially ELLs, write organized expository paragraphs is based on the theory of Vygotsky's (1978) Zone of Proximal Development. He believed students had two developmental levels: the actual development level and the level of potential development. The actual development level represents skills the students already possess. The problem-solving skills the students develop with the assistance of an adult represent potential development and are in the zone of proximal development. He posited that the zone of proximal development is important because it permits educators to determine the child's 
immediate future and his trajectory of maturing. Further, "The zone of proximal development can become a powerful concept in developmental research, one that can markedly enhance the effectiveness and utility of the applications of diagnostics of mental development to educational problems" (p. 71). So if we know how children will develop cognitively, we can develop programs that can help them reach their academic potential.

Feuerstein (1980) extended Vygotsky's Zone of Proximal Development by maintaining that when an adult mediates a child's experience by giving him/her a learning set and operational structures, the child's behavior crystallizes into sets and habits that form the prerequisites of proper cognitive functioning. Thus, if a teacher trains a student to solve a math problem and uses an intensive, well-organized process, the student will be stimulated to solve the problem using higher order thinking skills. He gives this example of a mother or caregiver giving instructions to a child:

On a higher level, when the mother, or other caregiver, uses verbal instructions interacting with the child, and these interactions transcend the use of imperatives by including explanations and generalizations, the effects will be perceptible in the nature of the child's approach to reality...the child learns to recognize ideas implicit in the content of the expanded verbal instructions (Feuerstein, 1980, p.21). 
Feuerstein termed this intervention Mediated Learning Experience (MLE). He maintained that these types of interventions help the child transcend the here and now to new modes of functioning and the development of new ways of acting appropriate to new situations. Further, Feuerstein states, “. . .MLE produces in the organism a propensity to learn how to learn, by equipping the organism with the tools necessary for this facility" (p. 25). Feuerstein's ideas about the nature of learning are significant because a key purpose of education is teaching students not just essential skills like reading and math but also learning how to learn. The Thinking Maps program embodies Feuerstein's beliefs when teachers use these maps to help students understand concepts

Thinking Maps represent a concrete example of Vygotsky's ZPD theory and Feuerstein's MLE theory because the maps produce intensively organized models that students can use to accelerate their learning when they depict concepts on paper and discuss the relationship among the concepts by writing a paragraph. When teachers help students construct these maps in a systematic fashion, they are mediating their students' learning about how concepts are related to one another. Further, when students write about how these concepts connect, they are developing academic English that is needed to be successful in school. The Thinking Maps program contains certain elements that help students translate their ideas onto paper and write well-structured compositions. These elements are scaffolding, constructivism, and acceleration. The 
following sections will explain each of these elements and how they help students, especially ELLs, become effective thinkers and writers.

\section{Scaffolding.}

As previously mentioned, many authors state that scaffolding is an important instructional strategy in helping ELLs learn English and manipulate higher-level concepts (Echevarria, Short \& Powers, 2006; August et al., 2008; Novak \& Canas, 2008; Rosenshine, 1997; The Education Alliance: Teaching Diverse Learners, 2006; Cobb, 2004). Typically, scaffolding is an instructional strategy teachers use to help students comprehend reading material. However, scaffolding can also be used as a them on cognitive strategy. It can structure related concepts to make it easier for students to represent paper. Scaffolding can also make it easier for students to add incoming information to these concepts. The use of scaffolding as an instructional strategy is supported by research that maintains the importance of teachers initiating activities that require students to process and apply new information (Rosenshine, 1996).Scaffolding can be readily applied to Thinking Maps in the way that concepts can be reproduced on paper. Teachers create a Thinking Map to connect related concepts and use scaffolding to help students form a writing outline from the map. In this way, a scaffold can be used by teachers to help students process information by taking the concepts from the writing outline and fleshing it out by writing expository paragraphs. An example of a 
Thinking Map used as a scaffold for writing is the Tree Map that was illustrated in Chapter One.

\section{Constructivism.}

According to Brooks and Brooks, (1999), "Constructivism is a theory of learning that places the quest for understanding at the center of the educational enterprise" (p. 150). Part of this process of understanding involves scaffolding in which a concept is broken down into its essential elements by using skills like classifying and compare and contrast. In this way, constructing understanding involves seeing the relationships between the components that make up a concept.

Constructivism and scaffolding form the basis of Thinking Maps when students use a map to illustrate a concept, and make meaning when they break down a concept or idea into its component parts on paper. According to Costa, "It is not the content stored in memory but the activity of constructing it that gets stored" (p. 95). Thus, Thinking Maps allows students to focus on critical thinking and use the map they create to design writing outlines that could be fleshed out into written paragraphs.

\section{Acceleration.}

In the past and continuing to the present time, remediation strategies are used with students who achieve below grade level. These students include those who are considered at-risk because they qualify for Free or Reduced Lunch or who speak a language other than English as their first language. The remedial philosophy is 
teaching students at their level in the hopes of bringing them up to grade level. Unfortunately, students in remedial programs are more likely to fall behind rather than reach grade level. (Stanford News Service, 1994). Stanford Accelerated Schools was started in 1986 by Henry Levin at Stanford University. He based this program on the philosophy that "How you define children has an awful lot to do with how you work with them" (Stanford News Service, 1994, p. 1). He believed that all students should be considered gifted, and the instruction they receive should accelerate, rather then remediate, their learning.

For several authors, the accelerated instruction concept is specifically applied to how vocabulary is taught in the classroom, especially those who are ELLs because of the direct effect vocabulary instruction has on student achievement (Gersten \& Baker, 2000; Marzano, Pickering \& Pollock, 2001; Feldman \& Kinsella, 2005). In particular, Gersten and Baker (2000) state that English language instruction must accompany “...thinking through and then verbalizing, in English, students' ideas regarding content areas" (p. 459). Rather than having students learn vocabulary words by looking them up in a dictionary and using the words in a sentence, the recommendation is for students to have more in-depth experience with words. This might involve students keeping vocabulary notebooks, in which the students define the word, come up with their own explanation of what the word means and create their own non-linguistic 
representation of the word. Then, the teachers would have the students periodically review the words' meanings (Marzano, Pickering \& Pollack, 2001).

Feldman and Kinsella (2005) give an example about how vocabulary words could be used in a written and oral activity with students. Students could be given a sentence starter about bullying. They could write down concrete examples of bullying on campus. Then they could compose two sentences elaborating on the prompt and use this information to present their examples orally. The acceleration model underlies the Thinking Maps Program because students are taught how to create visual representations of concepts appearing in their content area subjects and write about them in well-organized expository paragraphs. Further, the maps represent systematic instruction that takes students from their present learning state and pushes them to higher cognitive levels as they figure out how concepts relate with each other on paper. Equally important, the idea of using visuals like graphic organizers to help students, especially ELLS, use higher order thinking skills has been mentioned by several authors (Gersten \& Baker, 2000; Marzano, Pickering \& Pollock; Jackson, 2004).

\section{Studies using Thinking Maps.}

Various sources have reported that using Thinking Maps have improved test scores. As part of a doctoral dissertation 92 students taking two college classes for two semesters were divided into experimental and control groups. The study's purpose was reading to determine whether using maps with the experimental group would affect 
their scores on tests compared to the performance of those in the control group. The variables were fast reading, phonics, comprehension, scanning, structure vocabulary and word parts. The results were the students who used TMs had statistically higher scores in five of the seven variables used. As a result,, the author concluded that mapping made a significant difference on reading test scores (Ball, in Hyerle, Ed. with Alper \& Curtis, 2004).

In Mississippi, Pass Christian used Thinking Maps for one year with middle school students and reported their writing scores increased after one year's implementation from level 2.2 to level 3.0 (with 4.0 being the highest level) (Hyerle, Ed. with Alper \& Curtis, 2004). Nicolson School ( a K-6 school) used the writing program "Write from the Beginning" (based on Thinking Maps) and achieved the highest scores in their district on the state writing test. Rosalie Park, in their second year of implementation and Westside in year three of implementation achieved Adequate Yearly Progress (AYP) in all areas (reading, math, social studies and indicators - growth index) as per federal guidelines in 2003 (Hyerle, Ed, with Alper \& Curtis, 2004). While TMs may have had an impact on the test scores at Rosalie Park, Westside and Pass Christian, the findings at Nicholson School carry more weight because writing progress can be more directly attributable to a treatment based on using the writing program, "Write from the Beginning."

\section{Comparing Graphic Organizers and Thinking Maps.}


There are several similarities between graphic organizers and Thinking Maps. They present the information graphically in a similar way-using circles and boxes. Both are primarily used for reading comprehension. Also, they deal with similar skills like compare and contrast and cause and effect. Teachers use graphic organizers for various instructional purposes. The teacher chooses which graph to use with students depending on the skills he/she wants students to learn. The Thinking Maps Program, however, is presented as a staff development program that trains teachers in $\mathrm{K}-5$ to use these maps with students. The goal is training students to use these maps on their own as an integral part of their learning. Further, not only would students use these maps to graph the relationship between content area concepts, they would use them as writing outlines to represent the concepts' relationships on paper. Thinking Maps, in particular, can help ELLs organize their writing and develop academic English in two ways. One, using a Thinking Map allows them to communicate with precision, to use the "codes of power": higher order thinking skills and advanced literacy skills (Jackson, 2004). Equally important, the Thinking Maps Program provides cognitive terminology and a vehicle for capturing this language so ELL students can build their repertoire of cognitive skills (Jackson, 2004). Two, when ELL students use a Thinking Map to depict the relationship among concepts, they can use this map as an outline that delineates these concepts' meanings and how they relate to each other. Thus, when 
these students write a paragraph using these outlines, they are developing academic English in explaining the concepts and their relationship.

\section{Summary.}

Regarding ELLs and the techniques in helping them read and write in academic English, several questions are addressed in the literature. One is asking what are the challenges ELLs face in learning to read and write in academic English? The other is what techniques have been used or suggested to accelerate ELLs' writing abilities? The answers to these questions also adhere to the theory of writing as a process. In using graphic organizers, concept maps or Thinking Maps, text structure and instruction are explicitly expressed in visual form as concepts. As well, these maps can be used as outlines, that students, including ELLs, can use in producing expository paragraphs.

\section{Summary}

This literature review presents a theory of writing that has been used as a framework for writing instruction. The ideas presented by Hayes and Flowers (1982) and Scardamalia and Bereiter (1986) state that writing is a process that begins with generating an idea for writing, translating this idea into paragraphs and revising the compositions that are produced. As well, they maintained students would be successful in this process if a teacher models it for them. National data show that a large percentage of students, including ELL students, are not able to produce grade-level 
work in writing. This review presents several writing models that were used with students having writing problems especially those presented by Graham and Harris (SRSD) (1989,2002a)and Englert and Rafael (CSIW)(1992).

Also, challenges ELLs face in learning academic English and using this knowledge to write effective expository paragraphs is examined in the literature. The techniques helping these students acquire and use academic vocabulary involve scaffolding and creating outlines linking concepts. Visual organizers like graphic organizers and concept maps have been used with ELLs. These strategies scaffold concepts students can use to form outlines they can flesh out in writing expository paragraphs. Thinking Maps have been used in several school districts in California. Their chief benefit for ELLs is constructing a writing outline from mapped concepts. Using this outline, students could write well-organized paragraphs that demonstrate their understanding of the relationship among content area concepts.

\section{Implications}

An important reason for doing research in effective writing approaches is determining what methods will help students, especially ELLs, write more effectively. The question is, do using visual organizers like graphic organizers and concept maps help students work more effectively with concepts and use them to write more structured paragraphs? The empirical evidence is scant regarding using these strategies with ELLs. The same finding could be said for Thinking Maps as well. 
These strategies need to be studied empirically so their effectiveness in helping ELLs can be more authoritatively determined. In successfully implementing a writing program I think ongoing staff development for teachers is needed to implement these writing models. This idea is reinforced by a study of eleven teachers who were teaching process writing (Lipson, Mosenthal, Daniels \& Woodside-Jiron, 2000). They studied the methods eleven teachers used when they taught process writing to their students. The authors found that there was a great degree of variability in the way the teachers used different approaches. The study's authors believed that variation in implementation occurred because teachers were doing the best they could without sustained training. In this way, a writing system like Thinking Maps may take hold because it has been presented as a school-wide staff development program. Ongoing coaching sessions with teachers are offered during the first year of implementation. This type of model, coupled with in-depth and consistent staff development could help make research about writing models become a reality so students, especially ELLs, become more effective writers under their teachers' knowledgeable guidance. Thus, the Thinking Maps program represents a significant step forward to helping students write more effectively. Because it is presented as a K-5 program, students will receive ongoing, organized instruction about how to deconstruct concepts on paper and create writing outlines to structure their compositions 


\section{Chapter Three: Methodology}

\section{Introduction}

The Thinking Maps Program is a commercial staff development product elementary schools can buy. Teachers in K-5 are trained to teach these maps to their students. The maps are visual organizers that students can use to map concepts on paper, and they can also be used as writing outlines that help students to conceptualize this relationship by writing compositions to describe this connection.

There are several questions that frame this study. One, what is the impact of using Thinking Maps on students' expository text compared to writing where a Thinking Map is not used? Two, how do students believe that Thinking Maps impact their writing?

For this study, three fourth grade classes at three elementary schools were used in a school district that is located in a suburban area on the West Coast. Two of the fourth grade classes were from schools that use Thinking Maps school-wide as a staff development program. Each of these two schools was experimental. The other class was the control group. For the experimental groups at both schools, the teachers helped students create a Thinking Map they used to write a composition. In the control group, the teacher had students write a composition without presenting an instructional strategy before they wrote. 
The chapter is divided into three sections. The first section presents background information about how the Thinking Maps Program was implemented at School B, where I was the principal. The second section presents demographic information about the district and each school that participated in the study. This information includes the ethnic background of the students, the percentage of students who qualify for free or reduced lunch, the current Academic Performance Index (API) and fourth grade writing scores based on the California state-wide writing test. The third section explains data collection. One source of data was quantitative and dealt with the process for gathering writing samples. Also the way these samples were analyzed will be described. The analysis includes the statistical tests used to measure the effectiveness of using a Thinking Map to organize a students' expository writing versus those compositions where another writing strategy might be used.

\section{Data Sources}

There were two qualitative sources that I used. One was classroom observations when the three writing prompts were presented to the three classrooms and observing students write at least once every other week in these classrooms. The other data source included interviews with four students from each of the three classrooms about the writing they completed in class. In each classroom, the teacher chose a lowachievement ELL student, a high-achievement ELL student, a low achievement nonELL student and a high-achievement non-ELL student. When I observed in the 
classroom, these were the students I looked at as they are writing. Also, I interviewed these students directly after they wrote the third composition. The key question was, how does a writing strategy as presented by the Thinking Maps program impact student writing?

\section{Background}

When I was the principal of School B, I began to implement the Thinking Maps Program by arranging for the teachers to receive two full days of staff development training. At this time, they were given binders that contained the eight thinking maps and procedures to use in presenting each map to students. As principal, I came up with an implementation calendar for teachers. Kindergarten teachers were given two weeks to implement each map because it would take longer for them to orient their students to work with these maps. Teachers in grades 1-5 were given a week to implement each map. Teachers were told to display the students' products in the classroom so I could see them when I visited their classrooms. During the year, teachers were released from their classrooms so a Thinking Maps consultant could model a lesson using a Thinking Map and address teachers' implementation problems.

To study teachers' implementation in the classroom, I chose two upper grade classrooms. I visited each classroom for three hours. At that time, I watched teachers present a Thinking Map to students and watched them write compositions using the Thinking Map as an outline. I also asked students what they used to organize their 
writing and if Thinking Maps offered a strategy that helped them. In the fourth/fifth grade classroom, the teacher had the students use a Thinking Map when they were responding to literature like The Lion, Witch and the Wardrobe. The teacher in the fourth grade class used the map to help students write expository compositions like writing a composition about the California deserts.

When I was observing students work in these two classrooms, students probably felt a little awkward around me at first—at least the first time I visited them. This awkwardness demonstrated itself as shyness when I was interviewed them about writing. However, I do not think my presence had a discernable impact on their writing because it was clear to the students that their teachers were directing the assignments.

As a result of classroom observations, I looked at the work the students in these classroom produced using a Thinking Map. Students' work appeared to be well organized when they used the Thinking Map as an outline. This idea was confirmed when I used the same fourth grade classroom I had used to study program implementation as a case study six months later to compare compositions the students wrote before they used a Thinking Map with two compositions written on two separate occasions where a Thinking Map was used as an outline before they began writing. The teacher of this class agreed to participate in the case study and I wanted to use her class because she had the most experience with using Thinking Maps. I think the teacher agreed to participate in this study because she knew I was focused on how students 
were helped to use a Thinking Map in structuring their writing rather than evaluating her teaching ability.

The two groups of students I used for the case study were ELL and non-ELL students. I assessed their compositions using a rubric that measured how organized their writing was and how often they used complete sentences in their paragraphs. In comparing the pre-and post-test results for these two rubric areas, t-tests were used to determine if the differences were statistically significant. I found that the compositions of both groups of students were better organized when they used a Thinking Map than when they did not. This difference was statistically significant for both groups.

\section{District Background}

For purposes of confidentiality, the school district in which the two schools are located will be known as the South Bay School District. The total number of students it serves is 31,918 . The main ethnic groups are White (26\%), Hispanic (51\%) Asian (13\%) and African-American (3.4\%). Also, 38\% of the Hispanics are ELL students. The district is now in Program Improvement because, as a district, it has the missed the English Language Arts (ELA) targets of 35\% for the 2008-2009 school year and the $46 \%$ ELA target for the 2009-2110 school year. The percentage refers to the number of students in each major ethnic group who had to score proficient on the English Language Arts section of the California Standards Test (CST). 
As of last year, there were three elementary schools in the district that used the Thinking Maps curriculum throughout their schools. This year, the number of schools increased to nine. This growth occurred because program implementation appeared to be successful especially at School A where students were immersed in using the program. As a result, the idea was to expand a successful model by getting more schools to participate. Two of the three original schools with fourth grade classes were chosen for use in the study. The company that sells the Thinking Maps program estimated that 10,000 schools across the country are currently using this program.

\section{Participants}

The three schools participating in this study were chosen for different reasons. School A was chosen because it had been the first to implement the Thinking Maps program and intensified its use especially with ELLs. I thought it would be interesting to see how the students' writing in a $4^{\text {th }}$ grade classroom at this school compared with a $4^{\text {th }}$ grade classroom at School B that had implemented TMs one year later. For School C, the $4^{\text {th }}$ grade classroom that was the control group, a colleague had volunteered his school in which TMs had not been introduced to the staff as a staff development program. I readily took his offer because I had been the principal at that school years before, knew the school's layout and the office staff. However, my colleague chose the teacher who would be participating in this study, and I had no prior relationship with her. 


\section{School A.}

School A is located near a large public university campus. School A serves 425 students. The major ethnic backgrounds of the students are: Hispanic (79\%), Asian (10\%), Blacks (4\%) and White (2\%). The percentage of ELL students is $85 \%$. The percentage of students qualifying for free or reduced lunch is $95 \%$. This school was in California's School Improvement Program for several years because of its low CST test scores. It left this status, and its API score for 2009 was 798. Currently, the school's Academic Performance Index (API) score is 820, an improvement of 22 points. As a result of increasing the school's API, it has been nominated as a California Distinguished School for 2010. In 2008, 28\% of students scored proficient and above on the $4^{\text {th }}$ grade STAR Writing Test. The following year, $41 \%$ of the students scored proficient or above-an increase of $13 \%$. This school reported using the Thinking Maps Program for the past three years.

\section{School B.}

School B is located in the center of the school district. Its serves 500 students. The community is ethnically diverse with the following ethnic demographics: AfricanAmericans-(12.5\%); Asians-(13.8\%); Hispanics-(40.7\%) and Whites-(24.6\%). However, Hispanics comprise the largest ethnic group. Also, (40\%) of students are ELLs. The percentage of students who qualify for free or reduced lunch is $53 \%$. The school has made continuous process in improving its API scores. As a result, the school 
became a California Distinguished School in 2006 and was recognized as a Title I Performing School in 2007 and 2008. In 2008, the school achieved an API score of 809. Unfortunately, the following year the school's API score dropped to 798. The current year, the school's API score is 827, representing a growth of 30 points. In 2008, the year before Thinking Maps was introduced at the school, $43 \%$ of fourth graders scored proficient or above on the fourth grade STAR Writing Test. Last year, 54\% of fourth graders scored proficient or above on the STAR Writing Test-an increase of 11\%. School B has used the Thinking Maps Program for two years.

\section{School C.}

This school is located in the north central part of the district. It serves 708 students. The ethnic backgrounds of the students are: Hispanic(-62\%); White-(24\%); Asian(-2\%). Also, 37\% of the students are ELLs. The percentage of students who qualify for free or reduced lunch is $46.91 \%$. The API score for 2009 was 814 . The current API score is 852 representing a growth of 38 points. Regarding the fourth grade writing score, $61 \%$ of students were assessed as being proficient or advanced in 2008 . The following year, 2009, 63\% of the students were assessed as being proficient or advanced. Currently, this school is using the district's writing program, the Write Tools, for their writing curriculum. Table 3.1 below contains a visual representation of how the three schools compare demographically. 
Table 3.1

Demographic Characteristics of Schools

\section{Demographic Characteristics of Schools}

\begin{tabular}{|l|c|c|c|}
\hline & School A & School B & School C \\
\hline ELL & $85 \%$ & $40 \%$ & $37 \%$ \\
\hline $\begin{array}{l}\text { Free/Reduced } \\
\text { Lunch }\end{array}$ & $95 \%$ & $53 \%$ & $46.91 \%$ \\
\hline \multicolumn{3}{|c|}{ ETHNICITY } \\
\hline Hispanic & $79 \%$ & $40.7 \%$ & $62 \%$ \\
\hline Asian & $10 \%$ & $13.8 \%$ & $2 \%$ \\
\hline Black & $4 \%$ & $12.5 \%$ &.$\cdot$ \\
\hline White & $2 \%$ & $24.6 \%$ & $24 \%$ \\
\hline & & & \\
\hline
\end{tabular}

\section{Data collection methodology.}

Participant observer.

As mentioned previously, I brought the Thinking Maps Program to School B with the approval of the school's Staff Development Committee. I observed its implementation in two fourth grade classes. One of these classes was the subject of a pilot study in Fall of 2009.

As an observer, I looked at how students in the three fourth grade classes responded to the three prompts given in September, October and November. When I 
watched them write, I looked at how students structured their compositions with and without the use of Thinking Maps. Also, I visited each class once to week and observed how writing was taught and how students responded to this instruction when they wrote.

While I participated to a limited degree by observing students write, my role was as a participant. When I asked students questions about how they wrote and looked at their work in their portfolios, I engaged in a dialogue about writing and in that way I was an active participant.

\section{Data collection.}

There were two sources of data for this study. One source was quantitative and derived from the student scores on three compositions. The students were given three writing prompts—one in late August, October and November. After the students in the three classes wrote a composition using the prompt, I collected them. Using a rubric (found in Appendix A), the compositions from these classes were evaluated on the degree of organization of the students' texts as measured by how well the students' sentences cohered or held together in a composition.

Two qualitative data sources were used in this study. One was classroom observations. I visited each of the fourth grade classrooms when the three writing prompts were presented. For the experimental groups, a Thinking Map was used with students as a writing outline. For the control group, the students wrote a composition based on the instructional strategy that the teacher chose. These observations were 
important because I was able to see the differences in instructional strategies the teacher in the control group used versus those teachers in the experimental groups especially when the four interviewed students were writing a composition. Also, between the months of September and November, I visited the three classrooms at least once every other week when the students were writing compositions. These visitations gave me a more in-depth picture of how the writing strategies impacted the writing skills of the four interviewed students in each class. When I visited the classrooms, I observed the interviewed students write. When the teacher gave them an assignment, I noted how many sentences they wrote as they responded to her directions.

The other qualitative source was student interviews. I interviewed four students from each of the three schools. As previously mentioned, the teachers chose a lowachieving ELL student, a high-achieving ELL student, a low-achieving non-ELL student and a high-achieving non-ELL student. I asked them questions about what they write about and what help they seek when they have difficulty writing. Also, I asked them to choose a composition from their writing portfolios and say what they liked about it.

For those students in the TM schools, I asked them if they thought TM had helped or did not help or had no affect on their writing. The Writing Protocol can be found in Appendix C.

\section{Data analysis.}




\section{Quantitative measures.}

The main way to determine the impact of using a Thinking Map on students' writing skills is evaluating the degree of writing improvement using a rubric. This measure was done by comparing the students' writing a composition without using a Thinking Map to one in which that strategy was used. In each of the fourth grade classes for this study, the students wrote a composition in September near the beginning of school. The students were given a prompt such as writing about what did you do during the summer? They wrote a composition about this topic without using any instructional strategy including a Thinking Map.

In October, the teachers in the two experimental groups presented a Thinking Map to their students in preparation for writing an expository composition. The teacher helped students create a Thinking Map, and they used it as an outline in writing a composition. These compositions were written in the middle of October. The same process was used when students wrote the third composition. That is, the teacher helped their students create a Thinking Map that structured their expository compositions. These paragraphs were written the first week of November. In the control group, the teacher had the students write expository compositions in October and November. The control group teacher used no instructional strategy in preparing her students to address the prompt. 
A rubric was used to measure the effectiveness of using a Thinking Map to help students write expository compositions by comparing their texts to compositions that were written without using a Thinking Map. A scale of 1 to 4 was used; 1=Below Standard; 2=Approaching Standard; 3=At Standard; 4=Exceeds Standard.

The students received a score in four categories: Ideas, Organization, Details and Word Choice/Sentence Variety. Ideas are concepts or thoughts that flesh out the topic of a composition. Organization describes how well the sentences cohere within a paragraph. Details are sentences that delineate or expand on the topic sentence of a paragraph. The category of Word Choice/Sentence Variety deals with the quality of words the students select when they write compositions.

These scores were averaged so each student's paper received one overall score. These measures were used to evaluate each of the three compositions from the three classes. The evaluators were three retired teachers who became my Writing Assessment Team. Means were used to measure each of the rubric areas for the three compositions. Then t-tests were used to determine the significance of the scores based on the categories for each of the three schools: ELLs, non-ELLs, Whites, Hispanics, fourth graders, and fifth graders. The only school where the writing of fifth graders was not a factor was School B because no fifth graders were in the classroom.

To attain inter-rater reliability, the Writing Assessment Team evaluated the students' compositions. After the student work was collected, I sat down with the 
evaluators who used a rubric to assess the compositions. Their primary focus was using the four rubric areas of Ideas, Organization, Details and Word Choice/Sentence Variety. Please note that while the last rubric category "Word Choice/Sentence Variety" did not directly correlate to the use of TMs, I retained that category because it was part of the overall rubric and its results could be discarded later if necessary. The Writing Team did not know the identity of the schools or which classes were control and which were experimental.

Before the Writing Assessment Team began assessing the paragraphs, sample papers were taken from the collected paragraphs. Using the rubric, we decided what constituted a "1" level which represents "far below grade level"; a "2" "below grade level; a "3" "at grade level" and "4" "above grade level". These papers were models the Writing Team could refer to when they rated or scored the papers. This exercise ensured congruity among the evaluators' assessments. Also, the Writing Team assessed two compositions chosen randomly from each school. Then each evaluator said their rubric scores and, as a team, we determined how similar their scores were.

The compositions from the three schools were duplicated so each Writing Team Member had her own copy. When they finished assessing a paper, they put their scores on a sheet of paper marked only with the designation "School A", "School B", and "School C". Each evaluator had her own sheet so the reviewers did not know one 
another's scores. Students' names were not used. Instead, each student had been assigned a number by the classroom roster.

When the Writing Team Members turned in their scores to me, they were entered on an Excel spreadsheet by school. The participant students had four rubric scores for each composition they wrote that were averaged to obtain an overall score. After every writing submission, I entered the overall rubric score on an Excel spreadsheet and calculated the means scores for the rubric assessments for students at the three schools. T-tests were used to determine the significance of these scores among the three schools using the following groups: ELLs, non-ELLs, non-Hispanics, Hispanics, fourth graders, fifth graders.

When all the compositions were evaluated and mean scores computed, the following comparisons were made. The three schools were compared for each of the compositions and on each rubric score. Scores were compared based on the factors mentioned above.

I analyzed the results of these comparisons for significant differences between the Thinking Maps and non-Thinking Maps schools based on the rubric scores. In particular, I examined what impact language status (ELL v. non-ELL students) and ethnic background had within and among the three schools. Please see Table 3.2 below for a break-down of the data groups by school. 
Table 3.2

Data Groups by School

\begin{tabular}{|l|l|l|l|}
\hline & School A & School B & School C \\
\hline Total School & $\mathrm{N}=22$ & $\mathrm{~N}=25$ & $\mathrm{~N}=24$ \\
\hline ELLs & $\mathrm{N}=10$ & $\mathrm{~N}=4$ & $\mathrm{~N}=4$ \\
\hline Hispanics & $\mathrm{N}=16$ & $\mathrm{~N}=9$ & $\mathrm{~N}=8$ \\
\hline Non-Hispanics & $\mathrm{N}=6$ & $\mathrm{~N}=16$ & $\mathrm{~N}=16$ \\
\hline $4^{\text {th }}$ grade & $\mathrm{N}=5$ & $\mathrm{~N}=25$ & $\mathrm{~N}=14$ \\
\hline $5^{\text {th }}$ grade & $\mathrm{N}=17$ & -- & $\mathrm{N}=10$ \\
\hline
\end{tabular}

\section{Qualitative measures.}

As mentioned earlier, there were two sources of qualitative data. One source was student interviews. The other source was classroom observations that were conducted when students wrote the three compositions at each of the three schools. Also, I visited classrooms once every other week to focus on the four interviewed students to get a better understanding about how the writing strategies teachers used with students helped them write. This qualitative data source was important because it provided evidence about students' beliefs about the efficacy of TMs in helping them organize their writing. With the teacher's help, the students could construct TMs as a writing outline. However, if students did not consult these outlines frequently as they were writing, how valuable could this strategy really be? So the question I was trying to answer with the data gleaned from the following: How valuable were these writing outlines to students as evidenced by the frequency with which the students looked at the outlines while they were writing? Every time I observed in the classroom, I focused on 
observing the four interviewed students writing especially how often they looked at the writing outline they had created with the teacher's help. I took notes and wrote a transcript based on them. I perused the transcript and underlined what I believed were key words. I used this same procedure with the transcripts I generated from videotaping the twelve students. In this way, I tried to triangulate their rubric scores with observing them in the classroom and the results of their interviews.

I interviewed the twelve students right after they had finished writing the third composition. Their responses were video taped and transcribed to form a written record. The students' responses were coded to determine the major themes that were revealed. Five questions were posed to the students at each of the three schools. I added a question about Thinking Maps for the students at School A and B. Also, I added an additional question for students at School A asking them if they would use Thinking Maps in middle school. A copy of these interview questions can be found in Appendix B. In correlating these two sources I used the classroom observations to buttress the answers the students gave me about how Thinking Maps helped or did not help them write.

After I video recorded the students' interviews, I made transcripts of their answers. Using a highlighter, I marked words or phrases I thought were pertinent. I wrote these words and phrases down on a piece of paper. I narrowed this list by grouping together those words or phrases that had two or more of the same responses. 
After each of these responses, I coded them by noting, in parentheses, how many repetitions of the same reply there were. I correlated these responses to the questions. From this data, I came up with the following themes: Attitudes About Writing, The Writing Process, Responding to the Writing Prompt and Thinking Maps. I also included an additional topic that asked students to comment on a writing assignment they had completed. I included this part to see how students' attitudes about writing translated into the way they regarded their compositions. 


\section{Chapter Four}

\section{Introduction}

The purpose of this study is to answer two research questions: one, what is the impact of Thinking Maps on students' expository compositions and two, how do students believe Thinking Maps help them write? To answer the first question, the writing of students in three classrooms was assessed. In two of these classrooms, both experimental groups used Thinking Maps as a writing strategy. In the third classroom, the control classroom, the teacher taught writing using a different writing strategy. The students completed three compositions during a three-month period. The second research question investigated students' answers about whether they thought Thinking Maps helped them write. I obtained this information by interviewing students about various aspects of writing including whether they liked to write, what helped them write and whether they found Thinking Maps a helpful strategy in organizing their writing. I observed twelve student interviewees in the classrooms as they responded to the writing prompts to see if, in fact, they used a Thinking Map in developing their compositions.

This chapter is divided into three sections: one, analyzing the quantitative data; two, analyzing the qualitative data and three, describing the findings when quantitative and qualitative data sources are intersected. The first section presents the quantitative measures that were used to assess how using Thinking Maps helped students organize their writing. These measures were students' rubric scores given to them by a Writing 
Assessment Team composed of three retired teachers. The means of these scores were calculated by total school, grade level and demographic groups within each school. Mean differences for the various data groups are discussed along with statistical tests that were performed using the rubric scores.

The second section will present the results of student interviews and classroom observations when writing was taught using a Thinking Map to respond to the second and third writing prompts. The results of this discussion will answer the final research question about whether students believed using Thinking Maps helped them write. The third section will integrate the results of the quantitative and qualitative data. In doing so, it will seek to answer the question about what the relationship is between the two data sources and how they impact the answers to the two research questions.

\section{Presentation of the Quantitative Data}

To assess the students' writing, a rubric was used that measured Ideas, Organization, Details and Word Choice. A Writing Assessment Team composed of three retired teachers assessed students' writing. The results of these assessments were four scores for each student which were averaged into one rubric score. Then the scores for each school were averaged. Separate scores for the grade level and ethnic groups were averaged as a basis for comparing schools. The ethnic groups were ELLs, Hispanics and non-Hispanics. The grade levels were fourth and fifth graders. For 
School B, fifth graders were not a factor because the class contained only fourth graders.

\section{Rubric scores for prompt \#1.}

In the table below, Table 4.1, are the results of the first writing prompt using the means for the rubric scores. This prompt asked students to write an essay in which they talked about three things they did on their summer vacation. A copy of this prompt can be found in Appendix A. For this prompt, no Thinking Map or writing instruction was presented to the students at the three schools. Thus, this prompt was considered a pretest because Thinking Maps were not used at Experimental Groups A and B. So these rubric scores would form a baseline against which the rubric scores for Writing Prompts 2 and 3 in which TMs were used for the Experimental Classes (Schools A and B) could be compared with the rubric scores of the Control Class (School C). Table 4.1 below shows the rubric scores averaged for each school as a whole and broken down into data groups composed of English language level (ELL versus non-ELL), ethnic background and grade level. 
Table 4.1

Rubric Scores for Writing Prompt \#1

\begin{tabular}{llll}
\hline & \multicolumn{3}{c}{ Data Groups } \\
\cline { 2 - 4 } & $\begin{array}{l}\text { School A } \\
(n=22) 2.99\end{array}$ & $\begin{array}{l}\text { School B } \\
(n=25) 2.52\end{array}$ & $\begin{array}{l}\text { School C } \\
(n=24) 3.31\end{array}$ \\
\hline ELLs & $(n=10) 2.85$ & $(n=4) 2.48$ & $(n=4) 3.3$ \\
Hispanics & $(n=16) 2.97$ & $(n=9) 2.47$ & $(n=8) 3.15$ \\
Non-Hispanics & $(n=6) 3.09$ & $(n=16) 2.55$ & $(n=16) 3.39$ \\
4th grade & $(n=5) 2.73$ & $(n=25) 2.52$ & $(n=14) 3.3$ \\
5th grade & $(n=17) 3.07$ & & $(n=10) 3.01$ \\
\hline
\end{tabular}

1=Below Basic; 2=Basic; 3=Proficient; 4=Advanced

\section{Discussion}

\section{School contexts and pre-test performance differences.}

There were three factors that might have affected the rubric scores for the three schools. One characteristic is the way the classes were grouped. According to the teacher at School C, the Control Group, her students were homogenously grouped meaning her students achieved at a similar level which was at or above grade level. Students in the Experimental Groups, Schools A and B were heterogeneously grouped, and students' achievement levels ranged from above grade level to below grade level. At School B, in particular, one-third of the students were below grade level.

The second component was grade level. Students in the Experimental Group, School A and the Control Group, School C were in combination classrooms that contained $4^{\text {th }}$ and $5^{\text {th }}$ graders. In both of these classrooms, half of the $5^{\text {th }}$ graders had the current teacher in $4^{\text {th }}$ grade. These $5^{\text {th }}$ graders who had their teacher a second year 
tended to be more mature than the students in School B, the Experimental Group. The class at School B contained only $4^{\text {th }}$ graders and the level of maturity may have been lower in this class because many of the school's more mature $4^{\text {th }}$ grade students who could work independently while the teacher was working with the other grade level students, were placed, by necessity, in either a $3^{\text {rd }} / 4^{\text {th }}$ or $4^{\text {th }} / 5^{\text {th }}$ grade combination at the school.

The third factor deals with how language arts instruction, particularly in writing, was delivered to the students. At School C, the Control Group, the class is considered self-contained. That is, the teacher presents the curriculum, including language arts, to her students throughout the day. In the Experimental Groups, Schools A and B, some students are taught language arts from a different teacher other than their homeroom teacher, with whom the students spend most of their day. At School A, the $4^{\text {th }}$ graders get language arts instruction from an English Language Development (ELD) teacher. At School B, because the language arts classes are grouped by the CST scores, one-third of the students go to another teacher for language arts instruction. Thus, the students who are taught language arts from a different teacher other than their homeroom teacher might have been at a disadvantage because they did not get the benefit of receiving writing instruction from the teacher who administered the writing prompts to them.

However, the fact still remains that the Control Group had much higher rubric scores than the Experimental Groups (Experimental Group School A=2.99; 
Experimental Group School B=2.52; Control Group School C=3.31). One reason for this difference could be the writing program the teacher at the Control Group, School C, offers her students. While the district's writing curriculum, The 6 Traits of Writing (Culham, 2003) is the district's adopted curriculum, some teachers use other sources to teach writing. This was the case when I met with the teacher at School C before school had started. At that time, I told her that she could use strategies derived from the district's curriculum when she presented the second and third writing prompts to her students. She said she did not use the district's adopted curriculum as much as writing activities she pulled from different sources. Her statement was confirmed when I visited her classroom several times. During one visit, she was helping students write a narrative. At another time, students were working on writing a summary. Finally, she had students respond to a prompt by writing several sentences either on their own or with a partner. These activities did not appear to be pulled from the district's curriculum but rather from various sources she had. She also said she tried to have the students work on a writing assignment at least once a week. From these observations, one could say that the teacher's writing program and the frequency with which she had students write was a factor in helping her students achieve as writers. Yet, one would have to question whether students at School C would have achieved as high as they did on the first writing prompt if one-third of the students in that class achieved below grade level like those at School B. One can certainly argue that the teacher's writing 
program might help these students achieve higher scores than those at School B but they probably would not be as high as they are for this writing prompt.

\section{Rubric scores for prompt \#2.}

In Table 4.2, the results of the second writing prompt are presented. For the second writing prompt, the students wrote an essay about a favorite activity they like to do and three reasons why they like doing this activity. A copy of this prompt can be found in Appendix A. In reviewing these scores, one can easily see that these scores declined markedly as compared to the results of the first writing prompt in each school and for all the data groups (ethnic and grade level).

Table 4.2

Rubric Scores for Writing Prompt \#2

\begin{tabular}{llll}
\hline & \multicolumn{3}{c}{ Data Groups } \\
\cline { 2 - 4 } & School A & School B & $\begin{array}{l}\text { School C } \\
(n=22) 2.58\end{array}$ \\
& $(n=25) 2.26$ & $(n=4) 2.8$ \\
\hline ELLs & $(n=42$ & $(n=4) 2.06$ & $(n=4)$ \\
Hispanics & $(n=16) 2.61$ & $(n=9) 2.19$ & $(n=8) 2.68$ \\
Non-Hispanics & $(n=6) 2.53$ & $(n=16) 2.29$ & $(n=16) 2.86$ \\
4th grade & $(n=5) 2.39$ & $(n=25) 2.26$ & $(n=14) 2.74$ \\
5th grade & $(n=17) 2.64$ & & $(n=10) 2.88$ \\
\hline
\end{tabular}

1=Below Basic; 2=Basic; 3=Proficient; 4=Advanced

As previously mentioned, the rubric scores for the second writing prompt decreased greatly for all three schools. Comparatively speaking, the scores at School C, the Control Group, indicated a greater level of decrease than the scores at Schools A and B the Experimental Groups. When I read the students' papers, they appeared to 
have little difficulty in describing the topic which was talking about their favorite thing to do. However, many of them failed to talk about the other part of the prompt which asked them to give three reasons why they liked doing their activity. A copy of this prompt can be found in Appendix A.

While the first writing prompt asked students to think of three things they did during summer vacation, the second prompt required students to describe an activity and state three reasons why they liked doing it. Thus, many students may not have done well on the second writing prompt because it may be have been more challenging for them to come up with three reasons why they liked an activity versus describing three summer activities required by the first prompt. The Writing Assessment Team buttressed this observation by stating that students failed to address the prompt when they declined to state the three reasons why they liked doing their favorite activity. This observation may also explain why the rubric scores for the students at School C, the Control Group declined more those at School A, the Experimental Group, in particular. While the teacher at School A helped the students deconstruct how to write about the three reasons, the teacher at School $\mathrm{C}$ gave her students no guidance at all in addressing the prompt.

\section{Rubric scores for prompt \#3.}


In Table 4.3, the results of the third writing prompt are presented. In looking at the rubric scores, we see that the scores for Schools B and C have improved while School A's scores have declined.

Table 4.3

Rubric Scores for Writing Prompt \#3

\begin{tabular}{llll} 
& \multicolumn{3}{c}{ Data Groups } \\
\cline { 2 - 4 } & $\begin{array}{l}\text { School A } \\
(n=22) 2.31\end{array}$ & $\begin{array}{l}\text { School B } \\
(n=25) 2.39\end{array}$ & $\begin{array}{l}\text { School C } \\
(n=24) 3.04\end{array}$ \\
\hline ELLs & $(n=10) 2.09$ & $(n=4) 2.25$ & $(n=4) 2.95$ \\
Hispanics & $(n=16) 2.26$ & $(n=9) 2.38$ & $(n=8) 2.96$ \\
Non-Hispanics & $(n=6) 2.46$ & $(n=16) 2.4$ & $(n=16) 3.08$ \\
4th grade & $(n=5) 2.22$ & $(n=25) 2.39$ & $(n=14) 2.92$ \\
5th grade & $(n=17) 2.34$ & & $(n=10) 3.2$ \\
\hline
\end{tabular}

1=Below Basic; 2=Basic; 3=Proficient; 4=Advanced

As previously mentioned, the scores of School B the Experimental Group and especially School C, the Control Group, improved with the third writing prompt. The third writing prompt asked students to describe a special day they spent with their family and three reasons why they liked this day. A copy of the prompt can be found in Appendix A. School A's scores declined even in comparison with School B's. The only exception was non-ELL scores appeared higher at School A than School B. One explanation for the overall decline at School A may be due to the teacher at School A who had her students write their responses as a review of an event rather than describing the activity and giving three reasons why they liked doing this activity with 
their families. Thus, the teacher's introduction to the writing assignment affected the outcome of the students' final compositions.

The writing scores for School B, on the other hand, may have improved because the teacher spent more instructional time helping students deconstruct the prompt especially being able to write about the three reasons why they liked doing this activity with their families. She had them underline the important words in the prompt. She also told them what elements a composition should contain to be considered proficient (a rubric score of "3" or higher). Equally important, the scores for School B had improved across the board for all the demographic groups. From this data, one could conclude that non-ELLs appeared to benefit from using Thinking Maps as much as ELLs.

For School C, the teacher did not present a strategy for addressing this prompt. However, these students' compositions may have received higher rubric scores because they were more used to the format of talking about the three reasons than they were for the second prompt. Or the students at School C may have found it easier to write about the three reasons regarding an activity they did with their families than for the second prompt in which the students described their favorite thing to do. The idea that the quality of the students' compositions was higher for this prompt than for the second prompt was buttressed by a comment made by one of the members of the Writing Assessment Team. After reading the papers for the third prompt, she stated the 
compositions appeared to be better written, especially for Schools B and C because they were better organized.

\section{Rubric categories for the writing prompts.}

As stated in the literature review, Thinking Maps might be a valuable writing strategy for students because using the map might help students construct their knowledge so they can write well-organized compositions presenting what they know.

So the sub-rubric scores were examined to see if there was a relationship between these scores and the mean rubric scores.

In looking at Table 4.4, some patterns were apparent by looking at the numbers. For the first writing prompt, "Organization" received the highest score for all three schools. This pattern is repeated for the third writing prompt for School and C, the Control Group. For the Experimental Group, School B, "Ideas" received a higher score (2.46) than "Organization" (2.45) for the third writing prompt but the difference was only one-hundredth of a decimal point. 
Table 4.4

Writing Prompts by Rubric Category

\begin{tabular}{|c|c|c|c|}
\hline & \multicolumn{3}{|c|}{ Writing Prompt \#l } \\
\hline & School A & School B & School C \\
\hline Ideas & 3.03 & 2.59 & 3.35 \\
\hline Organization & 3.19 & 2.68 & 3.54 \\
\hline Details & 3.01 & 2.47 & 3.05 \\
\hline \multirow{3}{*}{ Word Choice } & 2.75 & 2.37 & 3.19 \\
\hline & \multicolumn{3}{|c|}{ Writing Prompt \#2 } \\
\hline & School A & School B & School C \\
\hline Ideas & 2.69 & 2.22 & 2.89 \\
\hline Organization & 2.63 & 2.14 & 2.83 \\
\hline Details & 2.49 & 2.11 & 2.69 \\
\hline \multirow[t]{3}{*}{ Word Choice } & 2.52 & 2.25 & 2.8 \\
\hline & \multicolumn{3}{|c|}{ Writing Prompt \#3 } \\
\hline & School A & School B & School C \\
\hline Ideas & 2.47 & 2.46 & 3.06 \\
\hline Organization & 2.28 & 2.45 & 3.19 \\
\hline Details & 2.2 & 2.31 & 2.89 \\
\hline Word Choice & 2.3 & 2.26 & 3.01 \\
\hline
\end{tabular}

As previously mentioned, "Organization" received the highest rubric score for all schools in the first writing prompt as well as for the Control Group, School C, for the third writing prompt. So in looking at the rubric scores for the three schools, "Organization" received the highest rubric score for the first writing prompt where each school had the highest overall rubric mean score of the three writing prompts. This pattern is also repeated for the third writing prompt for Control Group, School C and Experimental Group, School B where "Organization" came in a close second. What this pattern appears to show is that if students' compositions are strong organizationally, 
they receive higher mean rubric scores than if another rubric category gets a higher score. Thus, it would appear that there might be a relationship between "Organization" and "Total Rubric Score" at the school level. Hence, if "Organization" received the highest score, total school rubric scores were higher than if another category were chosen. For example, for the second writing prompt, "Ideas" received the highest score for the Experimental Group School A and the Control Group, School C. At the Experimental Group, School B, "Word Choice" received the highest rubric score for that school. The overall rubric score for all three schools was lower than the first where "Organization" received the highest score.

An additional question about "Organization" concerns the role of Thinking Maps in structuring students' compositions for the Experimental Groups at Schools A and B. In Chapter Two, one of the main reasons for students' using Thinking Maps was in helping them organize their writing. Yet, "Organization" did not receive the highest score for the Experimental Groups at Schools A and B when they used a Thinking Map for the second and third writing prompts. The "Organization" score did come in a close second for School B for the third writing prompt and the students' writing received a higher over-all rubric score than they did for the second writing rubric (Prompt $\# 2=2.26$; Prompt \#3=2.39). The question remains why did Schools A and B receive their highest overall rubric score and "Organization" was rated the highest of the subrubric scores for the first writing prompt when no Thinking Map was used? The reason 
might be that students received a high "Organizational" score when they addressed the first prompt by writing about three activities they did during their summer vacation. In reading the compositions of Schools A and B for the second prompt about their favorite activity, students' compositions were generally organized when they described their favorite activity. However, many of them did not address the second part of the prompt which was mentioning three reasons why they liked that activity. As a result, the Writing Assessment Team stated they gave students' compositions lower rubric scores than they did for the first writing prompt because students did not fully address the prompt. Hence, while TMs may help students organize their writing, it is equally important that they address the writing prompt to receive a score of proficient or advanced.

\section{Findings and discussion.}

While the first part of the quantitative data presented the means of the rubric scores for the three writing assignments with the three schools, the second part entails giving the t-test results on the rubric scores. These tests were performed to see if there were any significant relationships between the schools as a whole and between the various ethnic and grade level data groups. This test is most appropriate for the study because it tests changes in the same subjects under different circumstances. In this case, the same test subjects were observed at specific intervals over time. 
To begin with, the overall analysis of the mean rubric score data suggests that the use of Thinking Maps does not have a statistically significant impact on the students' expository writing skills. For example, Table 4.5 , indicates a sizeable difference in mean rubric scores between School C, the Control Group (3.045) and Schools A and B, the Experimental Groups combined (2.364) that is considered statistically significant. $(\mathrm{M}=3.045, t=4.885, p<.009)$.

Table 4.5

Comparison Between School C and Schools A\&B for the $3^{\text {rd }}$ Prompt

\begin{tabular}{lccc}
\hline & $\begin{array}{c}\text { Schools A\&B } \\
\text { (mean) }\end{array}$ & $\begin{array}{c}\text { School C } \\
\text { (mean) }\end{array}$ & $t$ \\
\hline Writing Prompt Score & 2.364 & 3.045 & 4.885 \\
\hline Significant at the 001 level & & &
\end{tabular}

The pattern is continued as we look at the results presented in Tables 4.6 and 4.7. Table 4.7 shows a comparison of rubric scores for all three schools between the first and third writing prompts $(\mathrm{M}=2.60, t=7.48, p=.009)$. If Thinking Maps had a positive impact on students' writing, the rubric scores would show an increase from the first prompt when TM was not used to the third prompt when it was applied a second time with student writing. Instead, results indicate a decline that is considered statistically significant. This pattern is repeated for School A in Table 4.6 in which the scores for three writing assignments declined steadily from Prompts 1 through 3 $(\mathrm{M}=2.31, t=6.29, p=.009)$. 
Table 4.6

Comparison Between Prompt land Prompt 3 for School A

\begin{tabular}{lccc}
\hline & $\begin{array}{c}\text { Prompt 1 } \\
\text { (mean) }\end{array}$ & $\begin{array}{c}\text { Prompt 3 } \\
\text { (mean) }\end{array}$ & $t$ \\
\hline Writing Prompt Score & 2.99 & 2.31 & 6.268 \\
\hline Significant at the .001 level & & &
\end{tabular}

Table 4.7

Comparison Between Prompt 1 and Prompt 3 for All Students

\begin{tabular}{lccc}
\hline & $\begin{array}{c}\text { Prompt 1 } \\
\text { (mean) }\end{array}$ & $\begin{array}{c}\text { Prompt 3 } \\
\text { (mean) }\end{array}$ & $t$ \\
\hline Writing Prompt Score & 2.942 & 2.598 & 7.479 \\
\hline Significant at the 001 level & & &
\end{tabular}

One finding was particularly noteworthy. That is, the writing scores of non-ELL students decreased significantly between the first and second writing prompt $(\mathrm{M}=2.31, t$ $=6.27, p<.009)$. While the scores of ELLs also decreased, it was not nearly as significant as non-ELL students. Table 4.8 notes a decrease in non-ELL scores. 
Table 4.8

Comparison Between Prompt 1 and Prompt 2 for Non-ELL Students

\begin{tabular}{lccc}
\hline & $\begin{array}{c}\text { Prompt 1 } \\
\text { (mean) }\end{array}$ & $\begin{array}{c}\text { Prompt 2 } \\
\text { (mean) }\end{array}$ & $t$ \\
\hline Writing Prompt Score & 2.964 & 2.602 & 7.596 \\
\hline Significant at the .009 level & & &
\end{tabular}

\section{Summary of quantitative data.}

The mean rubric scores for the three writing prompts with the three participating fourth grade classes were examined to see if Thinking Maps helped students write more effective compositions. The major finding was that, generally, for students in the experimental group (Schools A and B) Thinking Maps did not have a statistically significant impact on their writing. That is, they received their highest rubric scores when a Thinking Map was not used for the first prompt. However, the data also revealed that non-ELL scores fell more dramatically than those for ELL students compared to the mean rubric scores for prompts 1 and 2 . This was particularly the case when one compared the rubric scores of School C with the decline between Writing Prompts 1 and 2 particularly noticeable. The finding about ELLs might mean that they were more engaged in using Thinking Maps especially at School A than the other data groups. Also their teacher helped them to deconstruct the prompt by modeling how to write about the three reasons why they liked doing a certain activity. This last result is fully explored with the student interviews and the qualitative data findings at school A. 
Finally, non-ELLs, especially at School B, appeared to benefit from using Thinking Maps to a similar degree as ELLs as evidenced by the rubric scores for the third writing prompt. In looking at School B's scores, one sees an improvement if one compares these rubric scores to the second writing prompt. The improvement in scores affected all groups leading to the conclusion that non-ELLs received a similar benefit as ELLs in using TMs.

\section{Presentation of the Qualitative Data}

While the purpose of the quantitative data was to determine the impact of Thinking Maps on students' writing based on their rubric scores, the qualitative data investigated the study's second research question namely, do students believe that Thinking Maps impact their writing? There were two sources: Student interviews and classroom observations. At this point, one might ask why it was important to get the students' opinions about Thinking Maps since they have no say as to whether they use TMs in the classroom or not? The answer to this question might be that if the students thought using TMs were valuable they would be more inclined to use them with or without teacher guidance. In fact, one question that the students at School A were asked is if they would use a TM in middle school even if their teacher did not use it as a writing strategy. With classroom observations, four students in each of the three classrooms were observed as they responded to the writing prompts and developed their compositions. The classroom observations were important because they provided 
evidence for the students' beliefs about how TMs helped them write as expressed in the interviews. That is, if students believed using a TM helped them organize their writing, what data supported these opinions? The best evidence would be noting how frequently students consulted the writing outlines they had just made in writing their compositions. Therefore, the purpose of the classroom observations, especially when the teacher used a TM in helping students create a writing outline, was noting how often students referred to these outlines in writing these compositions. Thus, these classroom observations would provide evidence that students believed that TMs helped them organize their writing.

This section details the results of the qualitative data that were collected in the schools. This entailed looking at themes based on the students' interview answers and correlating them to how these students wrote in class. The information will be compared to answer the second research question which is how do students believe Thinking Maps help them write?

\section{Findings from the interviews.}

Regarding the first theme, "Attitudes About Writing", all twelve students said they liked to write. Three of them said they were excited about writing while three believed it was fun. Two said they liked writing because it was creative. Other responses included liking to write because it helped the student express his/her feelings and it provided a quiet time for the student. "I like to write because it is really fun. It's 
like your own world. And nobody really judges you about your writing because no one can say nothing bad when you're writing to someone else..." (High ELL Student at School B).

The second theme, "The Writing Process", asked students how they began writing a composition. Five of them stated they started making a Thinking Map. "When I begin writing, I always start with a map to help bring all of my ideas together"(High non-ELL Student from School A). Four students stated they would write a beginning for their story. Three students said they referred to the prompt in writing the main idea. Other responses included coming up with key ideas for the story and creating a title for the story.

The third theme, "Responding to the Writing Prompts", asked them questions about the three prompts they completed. Ten of the students stated they liked writing to the prompts. Four of the students, all from School C, said responding to the prompts was easy. One student said she did not like the prompts because she couldn't add a twist to the composition. The other student said he did not like the prompts because it was hard working with his imagination. When asked which one they liked the best, the third prompt (favorite activity with your family) garnered the most votes with five; the first writing prompt (summer activities) was second with four responses and the second writing prompt (favorite thing to do) had three replies. The students' responses about which prompt was their favorite was interesting because they were the most personal. 
Here are two examples: "My favorite one was the third one because I got to express my feelings on how I feel about my baby sister." (High non-ELL Student at School A) "I enjoyed the third one because I hardly go with all my family because some of them live very far away." (Low non-ELL Student at School A).

The fourth theme, Thinking Maps, involved asking students from Schools A and B if they believed Thinking Maps helped them. All the students believed the maps were helpful. The response that was repeated the most was "Thinking Maps helped me not to forget my ideas," and five students responded similarly. Other responses included "...the ability to check things off as you do them," "...easier to have the details and main ideas," and "...tells you what to write about next." Here are two extended responses: "They (Thinking Maps) have helped me with writing very much and I really enjoy doing the Thinking Maps. They really help me put all of my writing together and put them in sentences." (High ELL Student from School A). "I feel really good because you write the topic sentence on top but then you put details on the bottom." (Low ELL Student from School B).

From talking to the teacher at School A and the four interviewed students, I got the idea that students were immersed in the Thinking Maps process. That is, from Kindergarten to $5^{\text {th }}$ grade, students were trained to use these maps to organize their knowledge as well as to write. In particular, these students agreed their teacher was very influential in continually training them so they could create Thinking Maps on 
their own and use them in writing. "She (the teacher) helps us figure out... The way she explains stuff like the main idea, the facts, the details, the facts, the details and then the main idea"(Low-ELL student). Another student said, "She explains what map to use, she helps us color code, and she says like how she teaches us to write"(High ELL Student). (With the color coding system these students use, they underline the composition's title in green, the main idea in yellow and the details in red).

One of the most interesting questions I asked students regarded a composition they chose from their writing folders and to explain why they chose it. Of all the questions I asked them, they felt the most comfortable talking about their work. This question probably engendered the most variety of responses that were very positive. Here are several examples of students' responses.

"I chose this composition because it was one of my best works. The particular thing I like is it is interesting and now it's more interesting than before." (High nonELL Student from School B).

"I chose this because I really like Halloween and I kind of made it a little scary and funny at the same time and added a little twist to it. I liked it because I really like Halloween." (High non-ELL Student from School C). 
"I chose this composition because the Constitution is part of our country and it is the best I've written so far." (High ELL Student from School A).

The other responses can be found in the interview transcription Appendix D.

\section{Discussion}

From this evidence, certain conclusions can be drawn. One, students generally like to write. Many feel it is fun, and they are excited to write. Two, most of the students liked responding to the three prompts. Almost half of the students chose the third writing prompt as their favorite. Three, all of the students at Schools A and B believed Thinking Maps helped them. More than half of them indicated they began writing a composition by creating a Thinking Map. Also, the same number of students liked Thinking Maps because they would not forget their ideas when they used one. Students at School A indicated they were immersed in the Thinking Maps process because they worked with these maps since Kindergarten. They believed their teacher was helpful with this process because she helped them outline and color code their maps. From this data, one can conclude from the student interviews that they believed Thinking Maps helped them organize their writing. Not only did a number of them find these maps helpful in remembering their thoughts but used this process as a way of beginning a composition. This finding is buttressed with the classroom observations of these students as they used these maps to write. 


\section{Classroom observations.}

This section presents classroom observation notes of how the shadowed students at each school responded to the three prompts. When I went into each classroom, I focused my note taking on how these students responded to the teachers' instruction, especially at Schools A and B. More importantly, I observed how these students used a Thinking Map to create a writing outline and consulted it frequently to guide them when they write their compositions.

\section{School A.}

When I entered the teacher's classroom, I noticed that her classroom management procedures were highly structured. Before she presented the prompt, she ensured that all the students had the necessary materials and were focused on her directions. While writing instruction could not be provided for this prompt, the teacher did several things in preparing the students to write. She displayed the prompt on an overhead projector and had the students read the prompt out loud with her. Then she directed them to read it silently. After they finished reading, she asked them what season of the year was being mentioned. As a group, they said "Summer". She asked them how many reasons were mentioned in the prompt. They responded "three". She had them breathe and stretch. She told them to re-read the prompt before beginning to write. Several times during the writing session, she reminded the students to re-read the prompt. 
At this time, I had not chosen four focus students. However, I did notice that the students seemed very focused on writing. I also saw two students begin making a Thinking Map in preparation for writing. I observed that most students had written at least two sentences in fifteen minutes. Most students had written at least half a page when twenty more minutes had elapsed.

When I entered this class to watch the teacher prepare students for the second prompt, I had the four students I would be observing. The teacher read over the second prompt with the students. She went through all eight Thinking Maps asking students which one would fit this prompt the best. The class and she decided the Tree Map would be best so the students began preparing to make this map on paper. On the overhead, she modeled making a Tree Map about her favorite thing to do which was art. She had students share in pairs what their favorite activity was. Then she had students start making their own map about their favorite activity. All four of the students worked steadily at making the Tree Map. Then they began writing their compositions. One student looked at the dictionary and another at a thesaurus trying to find synonyms. Two other students looked at their Thinking Maps several times as they were writing.

For the third writing prompt, the teacher read it orally on the overhead. She told students they needed to think of a time they spent with their families that they really enjoyed. One of the students I shadowed said he could not think of anything. The teacher delved with him until he came up with a day at Great America. The teacher said 
this composition would be like a story re-tell and wrote the elements of a summary on the overhead. She had students do a "pair share" about what they were going to write.

The teacher asked students to share with one another which Thinking Map they would use for this prompt. I observed the four students sharing their ideas about which map they were going to use. The four students began making the map they were going to use which was a sequencing map. When they began writing, I noticed one student, in particular, look at her map while she was writing. The other three wrote steadily finishing two paragraphs within twenty minutes. When they finished working, we went to a conference room in the office for the interviews.

\section{School B.}

In presenting the first prompt, the teacher gave each student a copy. She read it to them aloud. The students began working. I noticed several students were not very focused on writing. Some of them wrote incomplete sentences they numbered one through three. Other students finished writing very quickly. Those students who were continuing to write for twenty minutes wrote at least one paragraph.

For the second prompt, the teacher said she had students think of three activities and discuss them with their parents to determine the best one to write about. On their desks, the students had a paper they were going to use in making a Tree Map for the prompt. As the teacher was explaining how to make the map, I noted all four students were paying attention to the teacher's directions and completing the first detail or 
reason on the map. They started completing the outline for the second and third details. The teacher called on two of these students to read what they had so far and they did. The teacher helped them decide on their title. The students began writing their compositions.

As I went to the four students' desks, I noticed one student was continually looking at this map as he wrote. The other three looked at their maps intermittently and wrote steadily. Three of them were continuing to write after twenty-five minutes. One of the students was done.

For the third prompt, the teacher gave each student a copy. She spent at least thirty minutes going over the prompt's requirements with them. She said that when students wrote, they would be writing as if they were taking a writing test for the state. She read through the prompt and had them underline key words. She told them the reader must understand the students' reasons and why their compositions must have three reasons and that one reason would be considered below standard. She asked them what they were supposed to write about. A student responded "a favorite day". She asked them to name some favorite days and wrote their responses on the board. She spent some time telling them they were only supposed to write about one day. She mentioned in the first paragraph that students needed to write some information about their event like who was involved and where the event was. She modeled the Tree Map using her topic-Thanksgiving 2010 on the overhead. She told me she was spending 
extra time on this preparation because she thought the students did not delineate the reasons clearly enough in their second compositions.

All four students paid attention while the teacher was explaining the assignment. Then they began making their outlines using her map as a model. All four students were done with their outlines within fifteen minutes.

Two days later, the teacher had the students re-read the prompt. She reviewed what they had discussed previously. She went over the fact that they had to have three reasons in their compositions. Each reason had to have a topic sentence with sentences containing supporting details. She wrote this on the board:

Reason Sentence \#1

Supporting Detail

Supporting Detail

Supporting Detail

She asked what detail sentences talk about. Two of the four students responded correctly. She went over using signal words for delineating the reasons.

When her instruction was finished, the students got out their Thinking Map outlines and began writing. They wrote steadily and two of them looked frequently at their maps as they were writing. When all had finished, we went to a vacant classroom for the interviews. 


\section{School C.}

I included School $\mathrm{C}$ in this section even though the teacher did not use a Thinking Map in helping them write. I did shadow four students to observe when they responded to the writing prompts. I did this to see if there were any differences in the way the shadowed students wrote.

The main difference between this school and the others is the teacher gave the students no preparation or instruction before they began writing. In each case, she gave the students a copy of the prompt and read it over with them. For the first prompt, she asked them if they had any questions and answered them. For the third prompt, I answered the questions students had. These questions were: Did the activity (family activity) have to take up the whole day? Could a friend be included in the activity? Can it be one family member? Could we have more than three reasons? After each of the writing prompts was given, students wrote steadily for at least thirty minutes. The students I observed were focused on writing and wrote at least half a page. When the four students finished responding to the third prompt, we went to the conference room in the office for the student interviews.

\section{Discussion.}

Much of the section on classroom observation was devoted to how teachers in Schools A and B prepared their students to write because it appeared to directly affect students' writing. For example, the teacher at School A directed her students to address 
the first prompt several times as they wrote. This helped to focus their writing and may have helped the students attain their highest rubric score of all three prompts. Similarly, the teacher at School B devoted at least thirty minutes to helping her students deconstruct the third prompt. The result was a higher rubric score than the one they received on the second prompt, and her writing preparation may have been an important factor in this result.

Regarding the students' use of Thinking Maps in writing, it was clear that students used them in Schools A and B for responding to the second and third prompts. As I observed the four focus students at each school, I saw them carefully completing their writing outlines and referring to them frequently as they were writing.

What was particularly noteworthy was how immersed the students at School A were with creating and using Thinking Maps. In particular, when they were getting ready to choose a map for the third prompt, the teacher asked them which map would be appropriate. Several students, without hesitation, told her which one they would use and why. When she directed them to begin working, they constructed their own Thinking Map without her assistance.

In correlating the student interviews with the classroom observation, several conclusions can be drawn. One, students believe Thinking Maps help them write. In both Schools A and B, after the students made these maps, they consulted them frequently as they wrote their compositions. Two, the way students at School A have 
been immersed in using Thinking Maps can be viewed as a model for the way Thinking Maps can be used successfully as a writing model in schools. Because these students have used these maps from Kindergarten to fifth grade, they have become part of their cognitive repertoire. That is, these students know which map can be used for certain purposes and are able to construct one without explicit teacher assistance. These students acknowledged having these skills and several maintained they would use them in middle school even if the teacher did not use them as an instructional model. Thus, the results of the interviews and observations demonstrated answers to the second research question, do students believe these maps impact their writing. The qualitative data suggested students really believe these maps had a positive impact on their writing, especially those at School A.

\section{Summary of Major Findings}

The main finding from the quantitative data was Thinking Maps did not appear to impact the writing of students in the Experimental classrooms at Schools A and B where the staff at these schools had been inserviced in this program. That is, at these two schools, the schools' rubric scores were the highest when a Thinking Map was not presented. Also, for School A, the rubric scores continued to decline from the first prompt to the third prompt in which a Thinking Map was used a second time with students. However, the data do reveal that the scores of ELLs at Schools A and B fell less dramatically between the first and second prompts than they did for the ELLs at the 
Control Group, School C. For the second prompt, the scores of ELLs at School A declined 43 points and 42 points at School B while the scores of ELLs at School C declined 60 points. Another comparison has been mentioned earlier in this chapter. That is, the decrease in ELL scores at schools A and B between the first and second prompts was less than that of non-Hispanic students at School C who scored the highest of the ethnic and language groups for the first prompt (3.39). The decline was slightly .53 slightly more than half a rubric point. What this data may reveal is TMs appear to benefit the writing of ELL students although not enough to be statistically significant. In reviewing the individual writing samples it was apparent that the ELL students were more actively engaged in using Thinking Maps. This finding was greatly substantiated by the student interviews and classroom observations from School A, in particular. All of the interviewed students at School A were Hispanic and three were ELLs. As stated in the literature review, these two groups appeared to struggle more with writing than non-Hispanic and non-ELL students. The interviewed students believed that Thinking Maps really helped them organize their thoughts so they could write effectively. They had equally strong opinions about how their teacher helped them use these maps to write. They stated their teacher drilled them in outlining the main idea and supporting details by using different colored pencils to highlight these components in their writing outlines. She also helped them deconstruct the writing prompts especially for the second writing topic. Further, students were able to show 
their facility with using Thinking Maps when they were able to choose a Thinking Map and construct it without the teacher's assistance for the third writing prompt.

Based on the qualitative data, it can be deduced that the use of Thinking Maps and teacher guidance help level the playing field for ELL students. Non-Hispanic students, especially those at School C, may tend to feel like they do not need to use a writing strategy like Thinking Maps to do well while the ELL students are more likely to grasp on and use the skills they gain through TMs. Also, the students at School C received no guidance in addressing the writing prompts. The idea that non-Hispanic students, especially those at School C did not feel the need to receive instructional assistance with writing is supported by their answers to the question of what things the teacher does to help them. Two of the interviewed students stated they didn't really pay attention to the instruction the teacher was giving. The other two stated that sometimes she presented a writing outline and told students how to begin a paragraph. The students' opinions were supported by the fact that the teacher offered no instruction before the students began addressing prompts two and three. At School B, while the interviewed students did not state that the teacher used Thinking Maps to help them write, they mentioned specific examples where the teacher helped them begin writing a composition. This assistance included suggestions about writing a topic sentence and making word choices. At School A, the teacher's assistance was closely tied with students using a Thinking Map as a writing outline. Within that context, she helped 
them write and differentiate main ideas and details and color-code them on their outlines. 


\section{Chapter Five}

\section{Introduction}

Evaluating the effectiveness of Thinking Maps as a writing strategy led to the formation of two research questions that drove this study. One, what is the impact of Thinking Maps on students' expository compositions. Two, how do students think TMs helped them write.

The first research question was investigated quantitatively by using three fourth grade classes. Two of these classes were experimental because their teachers used TMs in helping them write compositions. The teacher in the third class, the control group, used no instructional strategy in presenting the prompts for students to write. Students in the three fourth grade classes wrote three compositions between the months of late August to November. A team of three retired teachers assessed the three sets of compositions in four areas using a rubric. These four areas were averaged into one number that each student received for each composition. These scores yielded means, and t-tests were performed to compare the three classrooms as a whole with each other and with data groups at each school including ELLs, Hispanics, non-Hispanics, fourth and fifth graders. The quantitative data showed TMs did not have significant impact on students' writing. One finding that was gleaned from the data was the scores of nonELL students declined more dramatically than those of ELL students between the first and second writing prompts. This finding might mean that ELLs found TMs helped 
them write compared with non-ELLs who appeared to use no defined strategy when they wrote.

To answer the qualitative question, interviews were conducted with four students in each of the three classrooms. These students were asked questions about how they felt about writing and what helped them write. I also observed in these classrooms when the teacher presented the writing prompt so I could see how students used TMs in the experimental groups for the second and third paragraphs. The interviews with students revealed that they believed TMs helped them write. In observing students using TMs at the two experimental classrooms, I found that they created these maps and consulted them regularly in writing their compositions. These results support the finding that ELLs' writing scores, especially at School A, fell less dramatically than non-ELLs because they used TMs to organize their writing.

\section{Discussion}

Several conclusions can be drawn from the study's results. One is how TMs are used specifically with ELLs. At School A, because this program was used from kindergarten to $5^{\text {th }}$ grade, students gained experience in using them as a way of understanding concepts and as a writing strategy. Also, they developed facility with English when they went through the concrete experience of creating maps that linked various concepts. Further, they were able to develop their language skills by crafting well-written sentences that explained the relationship between concepts. This ongoing 
exposure to a defined program led students to feel confident about using these maps with and without teacher assistance. This experience also led them to write well enough so their compositions from the first writing prompt compared favorably with the control group school that was expected to do well since all of their students were either at or above grade level. An interview question I asked students from School A was if they would use TMs in middle school even if their teachers did not use them. They indicated they would. One student, in particular, said she would use TM because the strategy would give her an edge when her writing was compared with others in her class.

I believe the Thinking Maps program has the potential for improving student writing even though this opinion could not be proven statistically in this study. School A had a 2.99 for the first writing prompt which was slightly below proficient (3.0 was proficient). This was a higher than expected score because of the high percentage of ELLs (85\%) and a high percentage of students qualifying for free or reduced lunch (95\%) at that school. I believe students' use of Thinking Maps in previous grades had an impact on this score even though students were not instructed in creating a Thinking Map for this writing prompt. Equally important, when students at School A were able to create their own TMs without teacher guidance for the third writing prompt, they appeared empowered in taking control of organizing their writing. Thus, Thinking Maps may be able to help these students demonstrate their knowledge by helping them organize their thoughts so they can write effective expository compositions. 
School A's experience with TMs has implications for other schools who want to use this program effectively. Teachers at this school were trained to use these maps to help students learn the interrelationships among skills in reading and the content areas. Equally important, teachers were shown how to help students use these maps as writing outlines where students learned to map main ideas and the corresponding details. So students used these maps to write well-organized compositions in language arts and social studies. For example, one of the interviewed students showed me a composition he had written about the constitution. The teachers at School B, however, were only trained to use maps in constructing relationships among concepts. If I were the current principal of School B, I would meet with the principal at School A to see how her teachers' training differed from what my staff received. I would then arrange to get additional instruction for my teachers. Equally important, I would ask her how she ensured teachers used TMs consistently at each grade level. One suggestion could be having teachers meet in grade level groups each month and collaborate about how students used the maps for concept development and as a writing strategy. From her suggestions and my ideas, I would formulate a plan so teachers at School B would implement TMs more intensively at every grade level.

Finally, I learned from reviewing the students' writing and the rubric scores how important it is for students to address the prompt when they are composing. The quality of students' work can be high but if their essays do not effectively address the prompt, 
their work will probably not receive the score it could have. Jane Bell Kiester (2000) echoes this idea. "Unfortunately, when writing their essays, they often go off on these tangents and make the most egregious error they can possibly make on a writing test, they get off the topic" (p. 43). This problem was exemplified by the way the students responded to the third writing prompt at School A. The prompt asked students to think of a time they enjoyed with their families and three reasons why they enjoyed this activity. Instead of directing students to describe the event and then talk about the three reasons, the teacher had students write their response as a review of an event. Consequently, many of the students in her class failed to mention the three reasons and the class received a low assessment compared to the other two schools. On the other hand, the same teacher prepared her students for responding to the first prompt by reviewing it with them and asking questions about what the prompt was about. Also, she reminded students to reread the prompt while they were writing to ensure they were on topic. Also, when the teacher at School B realized her students had not done well on the second prompt, she spent thirty minutes deconstructing the third prompt with them. She had them underline the key words in the prompt. Equally important, she showed them how to outline the main idea and specific details for each of the three reasons. As a result, her students' writing received a higher rubric score than that of School A. From this result, I learned if students are to realize their writing potential, teachers must give them ongoing practice in deconstructing a writing prompt. After students know 
what the prompt requires, teachers should help them outline their responses. Vians (2010) echoes these suggestions in her article about how to teach a writing prompt. She states that having students restate the prompt in their own words helps them understand what the prompt is asking them to do.

The ability to effectively address a writing prompt is an important gateway skill for students to have. When they apply for college and graduate school, they will often have to write several essays in response to prompts within a certain time limit. If students are able to effectively address the prompt, they will have a better chance of producing their best written work which will augment their admissions portfolio.

\section{Limitations}

\section{Students grouped in classrooms.}

One limitation that may have affected this study's results is the way the students were grouped. As previously mentioned, the students in School C, the Control Group, were grouped so that most of the students were independent workers and achieved at grade level in language arts and math. By contrast, even though students at School A were in a combination class, their achievement level was more similar to the $4^{\text {th }}$ grade class at School B that was heterogeneously grouped. Thus, the students' writing at School $\mathrm{C}$ was more advanced than the other two schools even when Thinking Maps were used for writing prompts two and three at the other schools. This situation put Schools A and B in a disadvantaged position. Even when students at School A 
wrote more effectively than expected because of their language and poverty status, there was still an achievement gap between Schools A and C (2.99 vs. 3.31) that increased considerably in comparing Schools B and C (2.52 vs. 3.31) for the first writing prompt. This writing prompt was chosen for comparison because it was the strongest rubric score for all three schools. So the most Schools A and B could hope for was narrowing the gap between their schools and School C. It would have been very difficult for the writing scores of Schools A and B to equal or surpass those of the School C.

\section{Comparing the achievement of Fourth and Fifth graders.}

Two, another factor was one-third of the students were fifth graders while the remaining two-thirds were fourth graders. At School A, the writing scores were higher for fifth graders than those of fourth graders for the three writing prompts at School A and two of the three writing prompts for School C. The different grade levels at School A made determining the impact of Thinking Maps on students' writing skills complicated. Did the fifth graders at School A write better because they were more mature or had more exposure to using Thinking Maps as a writing strategy? Also, another factor was more than half of the fifth graders had their current teacher in fourth grade. This fact may cause these students to achieve at higher levels because they were acclimated to the teacher's instructional style and academic expectations. The idea that it was difficult to determine the effect of these factors on fifth grade writing at School A impacted the results of this study. 
Similarly, at School C, the fifth graders outscored the fourth graders in two of three writing prompts. Like the fifth graders at School A, more than half of them had their current teacher in fourth grade. They were also older than their fourth grade classmates. The question is which of these factors or both caused the fifth graders to earn higher rubric scores on two of the three writing prompts? Like the fifth graders at School A, this lack of certainty about which factors caused fifth graders to have better writing scores in two of the three prompts impacted the results of this study.

Three, some fourth graders in Schools A and B were not taught Language Arts regularly by the participant teachers. In the case of School A, the fourth graders went to an English Language Development class for language arts while the fifth graders remained with the teacher at School A. I discovered this fact when I did the third writing prompt in the classroom. When I arrived, I noticed several students were missing. After the students finished writing the prompt, I asked the teacher where the students were. She said they were getting Language Arts in a different room. As a result, the fourth graders were given the third writing prompt at a different time and day than the fifth graders. With School B, as previously mentioned, the school groups its language arts classes by CST scores. In the participant teacher's class, that meant onethird of her students went to a different classroom for language arts instruction. Hence, these different learning arrangements may have affected these fourth grade writing scores because the affected fourth grade students did not receive the benefit of the 
teacher's language arts instruction at Schools A and B especially when they used Thinking Maps with their students.

\section{Length of the testing period.}

Four, the testing period was very short. It began at the end of August and ended the last week in November. The testing period for School A, was even shorter because the teacher was leaving her class the last week in October. That meant the three writing prompts were given in a two-month period. This short testing period for the three schools may have affected the study because it was difficult to measure growth within such a limited time frame, especially for School A. If two months were added, perhaps a greater degree of growth would have occurred especially for the students at School B where the students were not as immersed in the Thinking Maps process as were the students at School A. Thus, the teacher would have had more time for students to practice using this writing strategy, and their writing abilities may have advanced with increased exposure to using Thinking Maps in creating their writing outlines.

\section{Variabity in writing prompt presentation.}

Five, even though I relied on principal recommendation to choose the best teacher at Schools A and C to participate in the study, I had to rely on their expertise for presenting the prompts, especially at School A. This became a concern when the teacher at School A presented the third writing prompt. Instead of directing students to describe the best day with their families and three reasons why this event was so special 
according to the writing prompt, the teacher presented the prompt as a summary of an

event. As a result, many of her students did not mention the three reasons and their compositions were given lower rubric scores according to two of the three writing assessment team members because their work did not address the prompt. I knew there might be a problem when the teacher presented the topic the way she did but I believed I couldn't say anything because I would be interfering with her instruction.

\section{Writing Prompt Topics.}

Finally, I chose the writing prompts because they dealt with subjects students might be able to write about; namely, their summer vacation, the activity they enjoy doing and a special event with their families. I also had them mention three reasons in each prompt. My goal was to have writing prompts that were similarly structured so if there were any variance in rubric scores, they could be ascribed to differences in student achievement rather than differences in how the prompt was presented. However, I found the second prompt, in particular, was difficult for the students at all three of the schools to use. This phenomenon really affected the study's results, because if the prompt had been reconstituted, students might have addressed it more effectively which would have been reflected in their rubric scores.

\section{Writing Assessment Team's Scoring.}

There was some variability among the Writing Assessment Team's scores for the writing prompts. Specifically, one evaluator's scores for School B were lower by a 
rubric score point (1.0) especially for the first writing prompt. While the total scores for School B were lower than expected compared to the other schools for the first writing prompt (School A=2.99; School B=2.52; School $C=3.31$ ), the scores of the other two evaluators appeared to balance out the lower scores of this evaluator. For a more indepth discussion of this topic, please see Appendix G.

\section{Recommendations for Further Research}

If we are to get a more definitive answer regarding the impact of Thinking Maps on students' writing, future studies need to be conducted. In doing so, several factors should be considered.

One, researchers should be careful in selecting the schools for study. That is, the chosen schools should be more alike in the way they are grouped by achievement and maturity levels. One suggestion would be the classes should be the same grade level and heterogeneously grouped. In that way, one could determine that the differences in rubric scores among the classes related to the efficacy of Thinking Maps rather than the differences in the way students were grouped. Further, the students should be with the same teacher for language arts. As previously mentioned, one problem encountered was one third of the students at Schools A and B had language arts with a teacher other than the one who was participating in the study. So one would have to question if the rubric scores of these classes might have been higher had the participant teachers taught them language arts every day. 
Two, when researchers meet with the participant teachers, they need to stress the importance of helping students deconstruct a writing prompt. In that way, students will have a better chance of producing their best work and more definitive findings will be obtained from the data. That means telling teachers that students should write as if they were taking a state writing test. Further, the researchers should remind teachers that any writing assessment team looks primarily at whether the prompt has been addressed. To that end, the researchers should review effective writing prompt preparation techniques the teachers should use with their students. For example, the teachers should make sure each student has a copy of the writing prompt. The teacher should have students underline important words in that prompt. The teacher should then stress with students the elements their compositions should have to be judged at or above grade level by the writing assessment team. Then the researcher would have the teachers using Thinking Maps instruct their students in making a writing outline to address the prompt. When the prompts are given to students and the teacher completes her presentation, the researcher should remind students to address the prompt before they begin writing. The teacher at School B used these procedures in presenting the third writing prompt. Her students' rubric scores probably improved as a result of the way she prepared her students to address the prompt. Also, the teacher at School A engaged in similar preparation with her students for the first writing prompt and their rubric scores were 
the highest of the three writing prompts and comparable to the rubric scores of School C.

Three, the researchers should modify the second and third writing prompts. I chose them mainly because I felt students could relate to them. A teacher had mentioned to me before I began the study that the more the students could relate to a topic, the easier it would be for them to write. So I chose personal experiences like a favorite activity and favorite event with the family for this reason. I also structured them the same way so any differences in writing would be ascribed to the students' responses rather than how the writing assignment was structured. That is, each assignment had the student describe the situation and then give three reasons why they liked the activity or event. Unfortunately, while this format seemed to work for the first assignment, students had difficulty with the second and third writing prompts. Thus, instead of having students mention three reasons, I would have them write one. For example, for the second writing prompt, this is how I would rewrite it: "Everyone has an activity that they enjoy doing. It might be playing an instrument or a sport. Think about what you like to do the most. Write a composition telling what you most enjoy doing and why you like this activity so well. Be sure to use specific details in describing your activity and why you enjoy doing it. Use descriptive verbs and adjectives to make your paper interesting to read." In taking out the three reasons, the 
focus is more equally divided between describing the activity and saying why they liked it which may be easier for students to address.

Finally, the study period should encompass six months or longer. The current study period was only three months. In the case of School A, the study period was even shorter at two months. Having a longer study period would enable researchers to determine if there is progress in the experimental schools over time especially in the case of School B. At that school, students were not taught Thinking Maps on an ongoing basis from Kindergarten to $5^{\text {th }}$ grade like the students at School A. If the teacher a School B regularly taught Thinking Maps to her students for six months, a researcher would be able to see if there was writing improvement that might be ascribed to Thinking Maps being consistently used as a writing strategy with students.

Thinking Maps did have an impact on student writing from the students' viewpoints especially those at School A. Unfortunately, their opinions did not match the results of the quantitative data analysis except that the scores of ELLs at School A did not decrease as much as those of non-ELL students. This finding seemed to indicate that Thinking Maps may help ELL students write but not powerfully enough to be supported statistically. Hence, future studies should determine whether the results of these data sources; namely, students' opinions and their compositions, can be more strongly related. If additional studies could determine that students' opinions could be validated by the quality of their compositions using Thinking Maps, then one might be 
able to assert definitively that Thinking Maps had an impact on students' writing based on their writing rubric scores. 


\section{References}

Asubel, D. (1963). The psychology of meaningful verbal learning. New York: Grune\& Stratton.

August, D., Beck, I. L., Calderon, M., Francis, D. J., Lesaux N. K., Shanahan, T., Erickson, F. \& Siegel, L. (2008). Instruction and professional development. In D. August \& T. Shanahan (Eds), Developing reading and writing in second-language learners. New York: Routledge.

Auman, M. (1999). Step up to writing. Longmont, CO: Sopris West.

Baker, S., Gersten, R. \& Graham, S. (2003). Teaching expressive writing to students with learning disabilities. Journal of Learning Disabilities, 36 (2), 109-123.

Ballard, K. D., \& Glynn, T. (1975). Behavioral self-management in story writing with elementary school children. Journal of Applied Behavior Analysis, 8, 387-398.

Banks, J., Cochran-Smith, M., Richert, A., Zeichner, K., LePage, P., DarlingHammond, L., Duffy, H. \& McDonald, M. (2005). Chapter Seven. Teaching diverse learners. L. Darling-Hammond, J. Bransford, P. What teachers should learn and be able to do. San Francisco, CA: Jossey-Bass. 
Brooks, J. G. \& Brooks, M. G. (1999). In search of understanding: The case for constructivist classrooms. Alexandria, VA: ASCD-Association for Supervision and Curriculum Development.

Bromley, K. (2007). Best practices in teaching writing. In L. Gabrell, L. Mandel Morrow and M. Pressley (Eds.). Best Practices in Literacy Instruction. New York: The Guilford Press.

Buchman-Deatline, A. \& Jitendra, A. J. (2006). Enhancing argumentative essay writing of fourth-grade students with learning disabilities. Learning Disability Quarterly, 29(1), 39-54.

Bui, Y. , Schumaker, J. B. \& Deshler, D. D. (2006). The effects of a strategic writing program for students with and without learning disabilities in inclusive fifth-grade classes. Learning Disabilities Research \& Practice, 21(4), 244-260.

Chang, K. Sung, Y. \& Chen I. (2002). The effect of concept mapping to enhance text comprehension and summarization. The Journal of Experimental Education, 71(1), 5-23.

Chris. How to educate English language learners through the use of graphic organizers. (September, 19, 2008). Message posted to http://www.associatedcontent.com/article/1021888/how to educate English language learners through the use of graphic organizers. 
Clarke, J. H. (1991). Using visual organizers to focus on thinking. Journal of Reading, 34(7), 526-534.

Cobb, C, (2004). Improving adequate yearly progress for English language learners. Learning Point Associates, Naperville: Ill. 1-7.

Culham. R. (2003). $6+1$ Traits of writing: The complete guide, grades 3 and up. New York: Scholastic Professional Books.

Dabbagh, N. (2001). Concept mapping as a mindtool for critical thinking. Journal of Computing in Teacher Education, 17(2), 16-24.

Echevarria, J., Short, D. \& Powers, K. (2006). School reform and standardsbased education: A model for English-language learners. Heldref Publications. Long Beach: CA, 195-210.

Englert, C.S., Rafael, T. E., Anderson, L. M., Anthony, H. M., \& Stevens, D. D. (1991). Making writing strategies and self-talk visible: Cognitive strategy instruction in regular and special education classrooms. American Educational Research Journal, 28, 237-372.

Englert, C. S., Raphael, T. E. \& Anderson, L. M. (1992). Socially mediated instruction: Improving students' knowledge and talk about writing. The Elementary School Journal, 92(4), 411-449.Englert, C. S., Stewart, S. R. \&

Hiebert, E. H. (1988). Young writers' use of text structure in expository text generation. Journal of Educational Psychology, 80(2), 143-151. 
Englert, C. S., Wu, X. \& Zhao, Y. (2005). Cognitive tools for writing: Scaffolding the performance of students through technology. Learning Disabilities Research \& Practice, 20(3), 184-198.

Englert, C. S., Zhao, Y., Dunsmore, K. Collings, N. Y. \& Wolbers, K. (2007). Scaffolding the writing of students with disabilities through procedural facilitation: Using an internet-based technology to improve performance. Learning Disability Quarterly, 30, 9-29.

Feldman, K. \& Kinsella, K. (2005). Narrowing the language gap: The case for explicit vocabulary instruction. New York: Scholastic, Inc.

Fraenkel, J, R. \& Wallen, N. E. (2009). How to design and evaluate research in education. ( $7^{\text {th }}$ ed.). New York: McGraw-Hill Higher Education.

Feuerstein, R. (1980). Instrumental enrichment: An intervention program for cognitive modifiability. Baltimore, MD: University Park Press.

Garcia-Sanchez, J. \& Fidalgo-Redondo, R. (2006). Effects of two types of self-regulatory instruction programs on students with learning disabilities in writing products, processes, and self-efficacy. Learning Disability Quarterly, 29(3), 181-211.

Gersten, R. \& Baker, S. (2001). Teaching expressive writing to students with 
learning disabilities: A meta-analysis. The Elementary School Journal, 101 (3), 251-272. Special Issue: Instructional Interventions for Students with Learning Disabilities.

Goddard, Y. \& Sendi, C. (2008). Effects of self-monitoring on the narrative and expository writing of four fourth-grade students with learning disabilities. Reading and Writing Quarterly, 24, 408-433.

Graham, S. \& De La Paz, S. (1997). Effects of dictation and advanced planning instruction on the composing of students with writing and learning problems. Journal of Educational Psychology, 89(2), 203-222.

Graham, S. \& Harris, K. R. (1989). Improving learning disabled students' skills at composing essays: Self-instructional strategy training. Exceptional Child 56)(3), 201-214.

Graham, S. \& Harris, K. (2005a). Improving the writing performance of young struggling writers: Theoretical and programmatic research from the Center to Accelerate Student Learning. The Journal of Special Education, 39, 19-33.

Graham, S., Schwartz, S. S. \& MacArthur, C. A. (1993). Knowledge of writing and the composing process, attitude toward writing and self-efficacy for students with and without learning disabilities. Journal of Learning Disabilities, 26(4), 237-249. 
Griffin, C. C., Malone, L. D. \& Kameenui, E. J. (1995). Effects of graphic organizer instruction on fifth grade students. The Journal of Educational Research, 89 (2), 98-107.

Grigg, W.S., Daane, M.C., Jin, Y., \& Campbell, J. R. (2003). The Nation's Report Card: Reading 2002. Washington D. C.: U.S. Department of Education.

Guzel-Ozman, R. (2009). Modified cognitive strategy instruction. Intervention in School and Clinic, 44(4), 216-222.

Hayes, J. \& Flowers, L. (1981). A cognitive process theory of writing. College Composition and Communication, 32(4), 365-387.

Hayes, J. \& Flower, L. (1986). Writing research and the writer. American Psychologist, 41(10), 1106-1113.

Hillocks, Jr. G. (1984). What works in teaching composition: A meta-analysis of experimental treatment studies. American Journal of Education, 93(1), 133-170.

Hyerle, D. (2004). Thinking maps as a transformational language for learning. In D. Hyerle, (Ed.), Student successes with thinking maps: School-Based research, results and models for achievement using visual tools. (pp. 116). Thousand Oaks, CA: Corwin Press. 
Isaacson, S. (2004). Instruction that helps students meet state standards in writing. Exceptionality, 12(1), 39-54.

Jackson, Y. (2004). Closing the gap by connecting culture, language, and cognition. In D. Hyerle (Ed.), Student successes with thinking maps: School-Based research, results and models for achievement using visual tools. (pp. 49-59). Thousand Oaks, CA: Corwin Press.

Jiang, X \& Grabe, W. (2007). Graphic organizers in reading instruction:

Research findings and issues. Reading in a Foreign Language, 19(1), $34-55$.

Kiester, J. B. (2000). Blowing away the state writing assessment test. Gainsville, FL:Maupin House Books.

Lane, K. L., Harris, K. R., Graham, S., Weisenbach, J. L., Brindle, M. \& Murphy, P. (2008). The effects of self-regulated strategy development on the writing performance of second-grade students with behavioral and writing difficulties. The Journal of Special Education, 4( 4), 234-253.

Lienemann, T. O., Graham, S., Leader-Janssen, B. \& Reid, R. (2006). Improving the writing performance of struggling writers in second grade. The Journal of Special Education, 40(2), 66-78.

Lipson, M. Y., Mosenthal, J., Daniels, P. \& Woodside-Jiran, H. (2000). Process writing in the classrooms of eleven fifth-grade teachers with different 
orientations to teaching and writing. The Elementary School Journal, 101(2), 209-231.

Marzano, R. J., Pickering, D. J. \& Pollock, J. E. (2001). Classroom instruction that works: Research-based strategies for increasing student achievement. Alexandra, VA: ASCD-Association for Supervision and Curriculum Development.

Merriam, S. B. (2009). Qualitative research: A guide to design and implementation. San Francisco, CA: Jossey-Bass.

Moore, D. \& Readance, J. (1984). A quantitative and qualitative review of graphic organizer research. The Journal of Educational Research, 78, 11-17.

National Assessment of Educational Progress. (2003). The nation's report card: Writing, 2003.

The National Commission on Writing in America's Schools and Colleges. (2003). The College Board.

Novak, J. Canas, A. J. (2008). The theory underlying concept maps and how to construct and use them. Available at: http:cmap.ihmc.us/Publications/ResearchPapers/TheoryUnderlyingConcept Maps.pdf.

Peterson, S. (2000). Yes, we do teach writing conventions! (Though the methods may be unconventional). Ohio Reading Teacher. 34(1), 38-44. 
Rafael, T. \& Englert, C. S. (1990). Writing and reading: Partners in constructing meaning. The Reading Teacher, 388-400.

Reid, R. \& Lienemann, T. O. (2006). Self-regulated strategy development for written expression with students with attention deficit disorder. Council for Exceptional Children, 73(1), 53-68.

Rosenshine, B. (1997). The case for explicit, teacher-led, cognitive strategy instruction. Paper presented at the annual meeting of the American Educational Research Association, Chicago, Ill, March 24-28,1997.

Scardamalia, M. \& Bareiter, C. (1986). Research on written composition. M. C, Wittrock, (Ed.) Handbook of Research onTeaching. American Educational Research Association.

Short, D. J. (2002). Language learning in sheltered social studies classes. Retrieved from http://0-vnweb.hwwilsonweb.com.opac.sfsu. Edu/hww/results/getRes...

Simmons, D. C., Griffin, C. C. \& Kameenui, E. J. (1988). Effects of teacherconstructed pre-and post-graphic organizer instruction on sixth-grade science students' comprehension and recall. The Journal of Educational Research, 82 (1), 15-21.

Stanford News Service. (1994, April 13). Accelerated schools: Building on success. 
Stoddard, T. (2006). Using concept maps to assess the science understanding and language production of English Language Learners. Presentation of the Second Institutional Conference on Concept Mapping. A. J. Canas, J. P. Nowak, Eds., San Jose, Costa Rica.

Stull, A. T., Mayer, R. E. (2007). Learning by doing versus learning by viewing: Three experimental comparisons of learner-generated versus author provided. Journal of Educational Psychology, 99 (4), 808-820.

Teaching diverse learners (2006). The Educational Alliance at Brown University.

Torrance, M., Fidalgo, R. \& Garcia, J. N. (2007). The teachability and effectiveness of cognitive self-regulation in sixth-grade writers. Learning and Instruction, 17, 265-285.

Vians, R. (199-2000). How to teach a writing prompt. Available at: http://www.ehow.com/how_4442775 teach_writing_prompt.html.

Vygotsky, L. S. (1978). The development of higher psychological processes. Cambridge: President and Fellows of Harvard College.

Weisman, E. M. \& Hansen, L. E. (2007). Strategies for teaching social studies to English-language learners at the elementary level. The Social Studies, September/October, 2007, 180-184. 
Wong, B. Y. L., Butler, D. I, Ficzere, S. A. \& Kuperis, S. (1996). Teaching low achievers and students with learning disabilities to plan, write and revise opinion essays. Journal of Learning Disabilities, 29, March 1996, 197-212.

Zimmerman, B. J. (1989). A social cognitive view of self-regulated academic learning. Journal of Educational Psychology. 81 (3), 329-339.

Zimmerman, B. J. (2002). Acquiring writing revision and self-regulatory skill through observation and emulation. Journal of Educational Psychology. 94(4), 660-668. 


\section{Appendix A}

\section{Classroom Rubric for Writing}

\begin{tabular}{|c|c|c|c|c|}
\hline \multicolumn{5}{|c|}{ Classruom Ruarie for Writing } \\
\hline & \multicolumn{3}{|c|}{$\begin{array}{l}\text { Use this rubric to score your writing task. Is gives you feecback on your strengths } \\
\text { and weaknesses in four areas of your writing. Lise it to belp you improve your } \\
\text { writing. }\end{array}$} & \multirow[b]{2}{*}{$\begin{array}{c}1 \\
\text { Below Stardand }\end{array}$} \\
\hline & Lxceeds Standarcs & At Standard & ${ }^{2}$ Aproaching Standará & \\
\hline & $\begin{array}{l}\text { Cleurly cowers all parts of } \\
\text { the writing ponowpt. }\end{array}$ & $\begin{array}{l}\text { Covers afl parts of the } \\
\text { writing prompt. }\end{array}$ & $\begin{array}{l}\text { Covers only parts of the } \\
\text { writing promot }\end{array}$ & $\begin{array}{l}\text { Cowers only anc part of the } \\
\text { writing prompt. }\end{array}$ \\
\hline Ideas & $\begin{array}{l}\text { licas are creative and } \\
\text { thoughtful } \\
\text { - lceas are original } \\
\text { - Purpose for writing is } \\
\text { clear. (to describe, to } \\
\text { retell an evert, to } \\
\text { persuade, to inform) }\end{array}$ & $\begin{array}{l}\text { - lóss are satisfactory } \\
\text { - lésus are andirary } \\
\text { - Rurpose for writirg } \\
\text { is understood. }\end{array}$ & $\begin{array}{l}\text { Tess are simple and } \\
\text { repotitive. } \\
\text { - ldess may be a list. } \\
\text { - Purpose for writing is } \\
\text { rot cleaz. }\end{array}$ & $\begin{array}{l}\text { - Leas ate iroomplete. } \\
\text { - Writing has few wonds. } \\
\text { - Purpose for writirg is } \\
\text { rot understood. }\end{array}$ \\
\hline $\begin{array}{l}\text { Oreasic } \\
\text { ation. }\end{array}$ & $\begin{array}{l}\text { Teas are connected and } \\
\text { flow smosthly from } \\
\text { beginring to end. } \\
\text { - Poirt of siew stays the } \\
\text { same. } \\
\text { - Writing stays on topic. }\end{array}$ & $\begin{array}{l}\text { - Icas are related but } \\
\text { may have some } \\
\text { choppy parts. } \\
\text { - Poirt of view stays } \\
\text { the same most of the } \\
\text { time. } \\
\text { Writing stays or } \\
\text { topic most of the } \\
\text { time. }\end{array}$ & $\begin{array}{l}\text { Jeas are not } \\
\text { conreted and may } \\
\text { ramble or jump } \\
\text { arourd. } \\
\text { - Point of view changes. } \\
\text { - Writing may rot stay } \\
\text { on topic. }\end{array}$ & $\begin{array}{l}\text { Idess are hard to follow } \\
\text { or do rot make serse. } \\
\text { Poirt of view is rot } \\
\text { clear. } \\
\text { Writirg does rot stay or } \\
\text { topic. }\end{array}$ \\
\hline Detasls & $\begin{array}{l}\text { Most ideas are } \\
\text { elaborated fully with } \\
\text { mearirgful reasons, } \\
\text { cetaik, or fsets with } \\
\text { examples. }\end{array}$ & $\begin{array}{l}\text { liess are stpported } \\
\text { with some reasons, } \\
\text { details, or facts with } \\
\text { examples. }\end{array}$ & $\begin{array}{l}\text { Teess are supported } \\
\text { with few reasors, } \\
\text { details, or taets with } \\
\text { examples. } \\
\text { - Sorre details may be } \\
\text { unrelated. }\end{array}$ & $\begin{array}{l}\text { Décs are not supported. } \\
\text { - Details are incomplete } \\
\text { or missing. }\end{array}$ \\
\hline $\begin{array}{l}\text { Word } \\
\text { Choike } \\
\text { Sentence } \\
\text { Varicty }\end{array}$ & 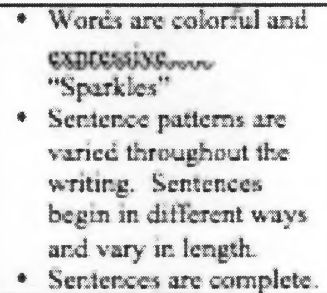 & $\begin{array}{l}\text { Wordis are conmon } \\
\text { of everyday. } \\
\text { - Serterse patterns } \\
\text { may be repetitive } \\
\text { and predictable. } \\
\text { - Most sentences are } \\
\text { complete. }\end{array}$ & $\begin{array}{l}\text { Words are common } \\
\text { and may be repetitive. } \\
\text { - Serterce pattems may } \\
\text { be short ard simple or } \\
\text { lorg zambling. } \\
\text { - Mary wentences may } \\
\text { rot be complete. }\end{array}$ & $\begin{array}{l}\text { Words are limited } \\
\text { andor confusing. } \\
\text { - Serterces are confusing } \\
\text { or difficult to read. } \\
\text { - Serterces are not } \\
\text { complete. }\end{array}$ \\
\hline
\end{tabular}


Appendix B

Writing Prompts

Prompt for the First Writing Prompt

Source: Writing Files of Teacher at School B

PROMPT FOR A $4^{\mathrm{TH}}$ AND $5^{\mathrm{TH}}$ GRADE WRITING SAMPLE

WRITING SITUATION

Everyone did a lot of different things during the summer. Some people went on trips, some did things around the home, some visited relatives,etc.

\section{DIRECTIONS FOR WRITING}

Using the writing techniques learned in the third and fourth grades, describe in detail three things you did this summer. Try to tell about them in such a way that the reader can almost feel like they were there with you. Use correct capitals and end punctuation as well as proper grammar. If you are not sure how to spell a word, spell it the way it sounds. 


\section{Prompt for the Second Writing Sample}

Source: Jefferson County Schools, Tennessee

Everyone has an activity that they enjoy doing. It might be playing an instrument, or a sport. Think about what you like to do the most.

Write a composition telling what you most enjoy doing and at least three reasons why you like this activity so well. Be sure to use specific details to support each of your reasons.

Use descriptive verbs and adjectives to make your paper interesting to read. 


\section{Prompt for the Third Writing Sample}

Source: Jefferson County Schools, Tennessee

Everybody enjoys spending time with their family. What is the best day you ever spent with your family? Think about the best day that you ever spent with about the best day you ever spent with your family.

Include at least three reasons in your paper that explain what made it the best day. Be sure to use specific details to support each of your reasons.

Use descriptive verbs and adjectives to make your paper interesting to read. 


\section{Appendix $C$}

\section{Interview Questions}

Interview Questions

1. Do you like to write? How do you feel when you write?

2. What about writing could be hard for you?

3. Students would choose a composition from their writing folders that they like.

a. Why did you choose this composition?

b. What do you like about it?

c. What things does the teacher do that helps you write?

4. When you think about writing a composition, how do you begin writing?

5. How did you feel about doing the writing prompts (summer vacation activities, an activity you like to do, an activity you liked doing with your family)? Did you find it easy to write about the topics? Is there one topic you liked the most? Why?

6. Schools A and B: Now that you have just finished using a Thinking Map, how do you feel about using one to write? Do Thinking Maps help you or not help you?

School A: When I talked with your teacher, she told me you use Thinking Maps a lot not only with her but with other teachers. Have these activities helped you in writing? How? When you move on to middle school, do you plan to use Thinking Maps for writing even if your teachers don't use them with you? Why/why not? 


\section{Appendix D}

\section{Student Interviews}

Transcription of Interviews with Students at School A-Tuesday, October 26, 2010 1. Do you like to write? How do you feel when you write?

Student \#8: I do like to write. I feel that it's fun when I write.

Student \#18: I really like to write. I think that it's exciting.

Student \#25: I like to write and I feel like I'm expressing my feelings when I write.

Student \#31: I like writing. I like to write because it gives me, like, a quiet time.

2. What about writing could be hard for you?

Student \#8: Yeah, sometimes writing is hard for me. Because

Student \#18: Sometimes it's hard for me to write because I'm uninspired.

Student \#25: Yes, writing is difficult for me sometimes because I get stuck and what should I write about and is it the best thing and it's like what should I write about.

Student \#31: It's hard writing sometimes because when there's a person that doesn't really explain it—it's a little hard to understand.

3. Choosing a composition

a. Why did you choose this composition?

b. What do you like about it?

c. What things does the teacher do that helps you write? 
Student \#8: a:I chose this composition because it explains story elements.

b:I chose it because it was like my best one.

c: She helps me figure out...The way she explains stuff like the main idea, the facts, the details, the facts, the details and then the main idea.

Student \#18: a: I chose this composition because it is the highest I've gotten so far in $5^{\text {th }}$ grade.

b: It's very interesting to learn the Constitution.

c: She helps us with the color coding.

Student \#25: a: I chose this composition because it was my first one that I wrote.

b: I like it because it's about an earthquake, you get to make your own title, it's like saying you're writing a newspaper article.

c: She explains what map to use, she helps us color code, she says like how she teaches us to write. It's very interesting.

Student \#31: a \&b: I chose this composition because the Constitution is part of our country and it is the best that I've written so far.

c: The teacher...like the whole class together she helps us do the map and then she explains to us the main idea, the details, the facts and details and then back to the main idea.

4. When you think about writing a composition, how do you begin writing? 
Student \#8: I begin writing with the main idea.

Student \#18: When I begin writing, I always start with a map to help bring all of my ideas together.

Student \#25: I think about what I'm going to write. I get an idea in my head. I write a map and I just write what I did from the map.

Student \#31: When I think about writing, I start with making the map. Then I start with the question.

5. How did you feel about doing the writing prompts. Did you find it easy to write about the topics? Is there one topic you liked the most? Why?

Student \#8: Question: Were those easy to write about? Yes. I like the second one because I like to write about my activity.

Student \#18: Yes (it was easy to write about those). My favorite one was the third one. Because I got to express my feelings on how I feel about my baby sister.

Student \#25: I liked the first one because I get to tell people about how I felt about my summer vacation and what I did. They were a little difficult but I can take a challenge and I really liked it.

Student \#31: I enjoyed the third one because I hardly go with all my family because some of them live very far away. I think they were easy because you gave us what to write about. 
6. Now that you have just finished using a Thinking Map, how do you feel about using one to write? Do Thinking Maps help you or not help you?

Student \#8: I feel that it really helps me a lot. Because it gets me to put down my ideas first and then I can write it on a piece of paper.

Student \#18: I think it is very helpful. It helps me so I don't forget my ideas

Student \#25: Thinking Maps really help me because if I get stuck and don't look at my Thinking Map, I look at my Thinking Map, and check the things off what I did so far. Student \#31: I think using Thinking Maps really, it really helps you. It helps by, when you're writing about something, it gives you, it tells you right here what to write about next.

7. Have these activities helped you in writing? How? When you move on to middle school, do you plan to use Thinking Maps in writing even if your teachers don't use them with you? Why/why not?

Student \#8: They have helped me in writing a lot. They help me so I do not forget things. Yes, because it would really help me.

Student \#18: They have help me in writing a lot. They help me bring all of my ideas $t$ ogether. Yes, it will help me bring all of my ideas together and not to forget.

Student \#25: They have helped me with writing very much and I really enjoy doing the Thinking Maps. They help me put all of my writing together and put them in sentences. Yes, because if I get off topic then they start something wrong. 
Student \#31: They helped me a lot. They help me because when I forget what I am writing about, it tells you. Yes, because if I use Thinking Maps, I'll get the highest grade than anybody else. 
Interview with Students from School B--12-1-10

1. Do you like to write? How do you feel when you write?

Student \#17: I like to write and the reason I like feeling when I'm writing is because when you're writing, it's like you're in your own world of writing.

Student \#22: I like to write because you get to write your own story when you think about it.

Student \#27: I like to write because it's fun just to make up a story and tell where the monster brings him and what happens to him.

Student \#14: I like to write because it's really fun. It's like your own world. And nobody really judges you about your writing because no one can say nothing bad when you're writing to someone. It's kind of fun because then you meet a new friend like you start having a friend and I used to keep on writing and it's really fun to write.

2. What about writing could be hard for you?

Student \#17: Writing could be hard for me because the one that is the most hardest for me is cursive because you learn a new letter, it's kind of hard for you to stick to it.

Student \#22: The hardest writing is cursive because when you write, you have to stick the letters together and the real writing aren't the same.

Student \#27: The punctuation and the neatness. Sometimes it's a little shaky so it's not neat. Sometimes it's boring. 
Student \#14: Well, I think the most hardest for me is spelling. I just have a lot of difficulty with it because sometimes I know how to spell the words but sometimes when I look at a word, I know it's not right but I don't know which letters to put in it.

3. Why did you choose this composition? What do you like about it? What things does the teacher do that helps you write?

4. When you think about writing a composition, how do you begin writing?

\section{Student \#17:}

3a.I chose this composition because it was one of my best works. Because it's long and interesting.

3b. The particular thing I like it is going to be interesting and now it's more interesting than it was before.

$3 \mathrm{cThe}$ things that she does to help me, she gives, the first time we came to school, the first prompt, she have us a title and then she helps us fill out that part if we need anything.

4. I begin by writing and telling who it is and who's telling about it and who is going to be on the adventure with you .

\section{Student \#22:}

3a. I choose this composition because I like how to describe the key.

3b. I like about it because you get to write your own story but the teacher makes you do the topic sentence and you write along 
3c. She puts, like words on the board so when I need help on a word, she could write it for me.

4. I begin writing the title of the story. Then I put the key ideas about and then the whole thing.

\section{Student \#27:}

3a. Because it's interesting to keep writing and it says--the prompt says "before his eyes" it's just fun because you could write the monster ghost or anything that got that person.

3b.It's just fun to make the characters.

3c. She helps me start off the thing. If I need help starting the topic sentence.

4. If you wanted like a monster, you put once upon a time so you know that it's not real.

\section{Student \#14:}

3a. I chose this composition because I thought it was kind of interesting.

3b.I actually wanted to write because it was about this key, how it was golden and how it was almost broken and when I opened the door because my dad-I haven't seen him hat much—so I'm writing about how I saw my dad and how I spent the whole day with him. Maybe it might come true or something. It's actually kind of fun imagining that you're doing something when you're not. It's like your own little world.

3c. Sometimes she begins the story and that makes it easier for me to finish it. She gives us the topic sentence. 
4. I first have to do my Tree Map so I can get most of the details. The hardest part making the Tree Map. Then it's easier to write the story like that.

5. How did you feel about doing the writing prompts? Did you find them easy to write about the topics? Is there one topic you liked the best? Why?

Student \#17: Not really because you have to start working with your imagination. And it's kind of hard. I like the summer activities because we got to go have a lot of fun.

Student \#22: Yes, because I got to write about the three different things. The summer vacation because you could remember all the fun things you did with your family.

Student \#27: Yeah, my favorite was my favorite thing I did with my family mom's work. The favorite thing to do, I because I had a lot of good times with my family.

Student \#14: Yes because I had a lot to write with it because sometimes because there's topics I can't write about because I haven't been there that much. I think the summer vacation is the one I liked the most because I had a lot to write about and I also had a lot of fun.

6. Now that you have just finished using a Thinking Map, how do you feel about using one to write? Do Thinking Maps help you or not help you? 
Student \#17: I like the Thinking Maps because they help you a lot while you're writing because once you do a Double Bubble Map, it tells you the differences and how they're the same. Yes (Thinking Maps help me).

Student \#22: I feel really good because you write the topic sentence on the top but then you put details on the bottom. Yes (Thinking Maps help me).

Student \#27: They're easy because if you forget like what you're going to write about, you'll always have that Thinking Map with a characters and you'll remember. Yes.

Student \#14: Yeah, it's real helpful. It's like it's already there but you had some words because it's actually easier to have the details and everything and the main idea. And like when you forget what you're writing, you'll look back and it's going to be there and make it easier to write. 
Transcript of Students at School C-Monday, November 15, 2010

1. Do you like to write? How do you feel when you write?

Student \#20 - I like to write and I feel very excited and creative when I write.

Student \#15-I do like to write. I feel really happy and excited to write. And I'm always creative when I write.

Student \#7-Yes, I do like to write. Most people do, in my opinion. I feel...it's fun. It's just I like to add humor to it. It makes me feel...I just feel happy.

Student \#14-Yes, I do like to write because I feel like I'm telling all my stories to somebody, telling what I'm thinking and like it's so much fun.

2. What about writing could be hard for you?

Student \#20 - I think, um, what could be hard, um, what would be hard about writing would be, um, for me, um, ( I asked if writing a summary would be hard, and what would it be)all of the...(all the things in the story or...) yeah, and the, um, main parts about it.

Student \#15-What would be hard for me is like when I write narratives I give some reasons but sometimes it's hard to think of some reasons.

Student \#7-For me I like fictional and stuff where I know I can add a little twist to it. But, um, when I can't I have to do it by the book and it's kind of hard for me. Student \#14-The thing that's hard for me is sometimes I feel like I'm just telling my story to somebody and I forget to do capitals or something. 


\section{When you think about writing a composition, how do you begin writing?}

Student \#20 - When I begin, I just think about a good beginning for my story and put some action in it and think about what, um, like how creative I should be.

Student \#15-I basically just like, look at the prompt, find the question, and then I revise the question then I make it the sentence. So that's my beginning sentence. Student \#7-I sort of do the same thing. Basically use the prompt to make my topic sentence and branch off that.

Student \#14-Well, I use the prompt and I like read it like two times. Then I try to find a question for it. That's kind of how I start it.

\section{How do you feel about doing the writing prompts? Did you find it easy to write} about the topics? Is there one topic you liked the most? Why?

Student \#20 - Yeah, it was easy because like for the thing I like to do I had some experience, I can write more about it and stay connected to another one, like skateboarding. (my favorite) the thing I like to do the best. Because, um, I like snowboarding a lot like one of my favorite fans is Shaun White. He does-he is a pretty good snowboarder. He likes to be, um, how do you say it, the champion of snowboarding and skateboarding like I do.

Student \#15 - It was pretty easy but some of them were hard. (My favorite) the best day I ever spent time with my family because I have a lot of best days that I spent time 
with my family. It's pretty easy just to choose one and then I just choose it, and I remember it and I write it.

Student \#7-I really didn't like to write them as much but they were easy. I didn't like them as much because I couldn't add a twist to it. I couldn't make it funny. (favorite one) Best day I had with my family because I don't know I just enjoyed that one the most.

Student \#14-Yeah, it was like pretty easy because I had a great vacation. (So did you like that one the best?) Yes, I like it because I got to write about my first time I went to Disneyland so it was pretty exciting to write about.

\section{Why did you choose this composition? What do you like about it? What}

things does the teacher do that helps you write?

Student \#14-Well, mainly because the teacher told us to. But another reason it was something I could add a twist to and make it really funny and I try to do that with my stories. Well, I like to make it funny and in the end do something you wouldn't think of-like as it turns out, it was just a costume-something like that. I never really listen to her but she does stuff like do basically just the factors...stuff like that...I don't know. Student \#20 - Because, um, this writing prompt tells us about how I like, um, the city, named Mikodis and could bring it like to a game try to find out, um, the, um, (Does she put stuff on the board and give you an outline or structure) Sometimes. (Does that help you?) Yeah. (Can you think of anything else she does with you?) No. 
Student \#7-_(Did you want to add anything? Go ahead.) She also does...like if you're going to add a twist to it, I got her last year and she said like I would never $\mathrm{f}$ orget or and she did like hooks and grabbers.

Student \#15-I chose this because I really like Halloween and I kind of made it a little scary and funny at the same time and added a little twist to it. I liked it because I really like Halloween. She basically, sometimes, outlines it and sometimes she says list the factors. (And that helped you?) Yes.

Student \#14-I chose it because this is mainly about the future and I like to talk about the future and because I thought it was really fun to write about. What I like it about it, um, just telling like describing what I really want to see about it. Sometimes she tells us how to begin a paragraph. 


\section{Appendix $E$}

\section{Classroom Observations}

Observation of Teacher at School A, 8-27-10 First Writing Prompt

In the prompt she asked them why a word did not have a period-share with partner - then asked why to the whole group and one person volunteered an answer. Had prompt displayed on the read it silently. She asked them what season was being mentioned, Winter, Fall, Spring or Summer. They said Summer. She asked them how many reasons are mentioned. They said three She had them breathe and stretch. She told them as soon as you re-read the cover sheet, you may begin. One of the students is making a tree map. One student is doing a sequence map. Most students, after 15 minutes, wrote at least two sentences. She reminded them to read the cover sheet. 20 minutes later, most students had written at least half a page.

My comments: She was a bit more direct at presenting the prompt. I would say also that these students were more focused and wrote longer than School B. 
Observation of Teacher at School A, October 13, 2010

Student Numbers: $8,18,31,25$

$10: 20$

Students shared answer with partners: What map would be the best to use? She went over each map and why they wouldn't fit

$10: 22$

Students folded paper in two; everybody writing and preparing

$10: 25$

Boys and girls either writing or looking at the board

Girls talking about favorite activity

$10: 28$

Guys already shared; waiting patiently

$10: 30$

One of the boys checking the spelling of hobby; girls sharing with each other $10: 36$

Student \#31 waiting for their first topic

$10: 35$

Student \#18 helping Student \#9; boys writing details; girls waiting on outline Student \#18 waiting patiently; 
Student \#25 following outline closely; she shared answers with partner $10: 40$

Student \#18 continuing to complete TM

Student \#31 working on completing the last detail

Student \#25 waiting—-talking with partner

Student \#18-ten fingers up; talk about what you do after TM; Student \#18

talking to Student \#19 about writing the topic sentence; number sentence

Teacher asked what words she didn't want to hear: first, second, third

10:45 Transition;

Student \#25 had hand raised

Student \#31 —-hand raised

Student \#25 tried to answer-teacher redirected her

Student \#31 was called on-responded

$10: 47$

Student \#18 wrote words in notebook

Student \#31 paying attention;

$10: 48$

Student \#31 wrote transition word down

Student \#25 wrote down check

Student \#18 had his hand raised for question; he wrote down answer 
Student \#25 waiting along with Student \#18

Student \#31 looking at TM

Student \#18 sharing information with Student \#9

Everybody taking out thesauri and looking up word

Student \#18 beginning to write composition

Student \#31 wrote down sentence and stopped.

All students started writing

11:03

Student \#25 writing and looking at map

11:05

Student \#8 writing paragraph; map in front of him

Student \#18 wrote first paragraph; looking at dictionary

Student \#25 beginning to write second paragraph

The teacher used Student \#8 paper as a model.

Student \#31 finishing first paragraph

11:09

Student \#25 beginning to write third paragraph

Both Student \#18 and Student \#8 writing a long first paragraph;

Student \#18 just checked off something off on his TM;

Student $\# 8$ just writing $2^{\text {nd }}$ paragraph —using the dictionary to look up a word 
Student \#25 just completing the first page with her $3^{\text {rd }}$ paragraph

Student \#31 still writing $1^{\text {st }}$ paragraph half a page down

\section{$11: 13$}

Student \#31 still working on $1^{\text {st }}$ paragraph

Student \#25 beginning to write $2^{\text {nd }}$ paragraph

Student \#18 finished page 1-has dictionary open

Student \#8 finished writing-reading a book

Student \#25 finished writing 
Observation of Teacher at School A.

October 26, 2010

Third Writing Prompt

Note: During this period, I observed the wrong student so I will not include the observations I made about the wrong student.

Student \#8 said he didn't have an idea ( a day he spent with his family); Then he thought about Great America.

Student \#8 wrote down the answer-story re-tell; the teacher had them write different elements of a summary

9:30

Student \#8 writing

Student \#31 sharing with Student \#8 about family experience

Student \#25 sharing with student

All 4 students sharing their ideas

Student \#8 volunteered the Brace Map as a possible map to use 9:40

Student \#31 said what map she was using

Student \#25 thinking about titl

$9: 42$ 
Student \#31 and Student \#8 erasing-began writing TM

Student \#25 thinking about what she's going to write on her TM

Student \#31 making a sequencing map

It looks like Student \#25 is making a sequencing map

$9: 52$

Student \#8 and Student \#31 doing a sequencing map; Student \#25 doing the same

Student \#31 and Student \#8 continuing to work on outlines

The teacher asked my interviewees if they were ready to write-they indicated they

were-she told them when they were done they would go with me

Student \#31 and Student \#8 beginning to write

Student \#25 continuing to complete TM

10:00

Student \#31 writing first paragraph; same with Student \#8

Student \#25 starting to write $2^{\text {nd }}$ paragraph

10:05

Student \#31 writing $2^{\text {nd }}$ paragraph

Student $\# 8$ writing $2^{\text {nd }}$ paragraph after writing introductory paragraph

Student \#25 talking to student; writing $2^{\text {nd }}$ paragraph after writing introductory

paragraph; then writing; then talking

Student \#8 thinking; looking at map; not continuing to write 
Student \#25 started to write $3^{\text {rd }}$ paragraph

Laura continuing to write

Student \#8 thinking; looking at TM

The teacher asked participants how they were doing; they all said they were doing fine.

$10: 10$

Student $\# 8$ continuing to write $2^{\text {nd }}$ paragraph

Student \#31 continuing to write long $2^{\text {nd }}$ paragraph

Student \#25 "going to town" writing $4^{\text {th }}$ paragraph

$10: 15$

Student $\# 8$ continuing to write $2^{\text {nd }}$ paragraph

Student \#31 almost finished the first page writing $1^{\text {st }}$ paragraph; she just went to $2^{\text {nd }}$

page

Student $\# 25$ almost completing $1^{\text {st }}$ page; on to $2^{\text {nd }}$ page

$10-27-10$

$3^{\text {rd }}$ Prompt for $4^{\text {th }}$ graders

Teacher presented format:

Character

Setting

Problem — where you are, what you did and the ending 
Observation of Teacher B, 8-25-10

The teacher presented the writing sample to the students. The writing is not as advanced (as that at School A). Some students wrote incomplete sentences that were numbered. Some students finished very quickly. One-third of the students were still writing after 20 minutes. Students who were writing at almost 10:00 wrote at least one paragraph. 
Observation of Teacher at School B, 10-13-10

Purpose of lesson: Teacher presenting outline-helping students supply details for pen pal letter

Teacher showing them the outline on the board; Students writing what she wrote on the board

$9: 45$

Students writing down their height

Student \#17 continuing to writing details

All 3 students on task and doing the same activity as Student \#17

Students writing down how long they've been at School B

Student \#27 on task but pounding hands together

9:50

Students continue to add details as teacher directs them

Student \#14 reading details

Student \#17 didn't look at paper as teacher directed but waited attentively for the teacher

Teacher asked Student \#22 why the " $\mathrm{x}$ " was used—she tried to answer (I don't remember the response) not correct; Student \#22 asked if we transfer details from outline to paragraph; Student \#22 asked if there were 2 Walk a Thons per year; teacher replied no but complimented her on askin 
Teacher: What's important to say about the Walk a Thon (WAT)

Student \#27: Students got snacks

Teacher: What were some of the prizes?

Student \#27: Food and a rocket pen

$9: 57$

Teacher asked students about WAT; Student \#27 answered questions about who was in the WAT

4 students writing details she wrote on the board

Students wrote number of laps walked

Teacher: Why do you like to walk in the WAT?

Student \#27: the D.J.

All wrote down why they liked to participate in the WAT

Teacher showed Student \#27 paper to class as a sample of a good outline 
Observation of Teacher at School B 10-14-10

$9: 38$

Student \#14: Teacher asked her what the $3^{\text {rd }}$ topic was. She answered correctly. (At this point, the students wrote the paragraph of introduction and the topic sentence of the second paragraph. They all had written down the topic sentence for the second paragraph.)

4 students listening to teacher's explanation.

The teacher invited me to help students.

The teacher asked what the next paragraph would be about. Student \#22 answered correctly.

4 students listening to what she's saying.

$9: 45$

Student \#22 looking at outline and writing $2^{\text {nd }}$ paragraph. Then she looked at the outline and began writing the $3^{\text {rd }}$ sentence in the paragraph.

Student \#27 looking at outline and writing I helped Student \#22 write a sentence about her brothers.

$9: 50$

Student \#27 taking a small break; then looked at outline Student \#14 continuing to write the $2^{\text {nd }}$ paragraph-looking at Student \#17 continuing to write $2^{\text {nd }}$ paragraph 
Student \#27 and Student \#14 continuing to write

Student \#22 continuing to write.

9:54

All 4 students continuing to write $2^{\text {nd }}$ para.

done with the $2^{\text {nd }}$ para. She said yes. I nodded my head indicating she should go on.

Student \#17 writing $3^{\text {rd }}$ para. About Walk a Thon (WAT)

He and 2 other students failed to start a new para. About WAT (Student \#22 was the only one who indented properly)

I mentioned to the teacher that 3 of the students I was shadowing failed to indent for the $3^{\text {rd }}$ para.

The teacher asked Student $\# 17$ what should the topic sentence for the $3^{\text {rd }}$ para. She got his paper and used it as an instructional model; she showed them the symbol for paragraph and had them put it in front When they wrote their final copy they would indent when they saw that symbol.

I showed Student $\# 27$ to indent by erasing and moving the first word of his $3^{\text {rd }}$ para. In. It was not what she wanted because he had not written the first sentence for that para. She had him erase it and write the sentence he omitted.

She told Student \#17 to erase the last sentence he had written at the bottom of the first page and write it at the bottom of the second page.

She told them to put this paper in their planners and they would finish it later 
Observation of Teacher at School B

October 27,2010

TM for $2^{\text {nd }}$ prompt

The teacher told me she had students think of 3 activities-discussed with parents so they would have something to say

(uses Tree Map for varied purposes; pen pal letter) 1 paragraph about favorite activity

Student \#27 said a check was used to indent a paragraph

Student \#17 listening to teacher's explanation

Student \#14 - paying attention to teacher's direction

Student \#22-paying attention

Student \#27 raising his hand-Student \#14 as well

Student \#17 answering teacher's question

Student \#14 answered the question

10:45

Student \#17-made first detail box

Student \#22-wrote first set of details

Student \#14-thinking

Student \#27- erasing writing; boxing the topic sentence

10:50 
Student \#17 starting on second detail; continuing to write; thinking Student \#27—starting to write the first detail

Student \#22-looking at first set of details

Student \#14—getting help from teacher to write the second detail $10: 57$

Student \#27—did two sets of details—starting $3^{\text {rd }}$

Student \#14 —adding a detail to the first set

Student \#17-adding details to $3^{\text {rd }}$ set

11:00

Student \#17 continuing to write- $-3^{\text {rd }}$ set of details

Teacher helping Student \#22 to add details

Student $\# 14$ adding details to $2^{\text {nd }}$ set

11:06

Student \#17-finished—reading

Student \#27-finished-helping a student

Student \#14-adding to details

Student \#22— done

$11: 12$

Student \#22—-teacher called on her—she read from her paper

Student \#27-volunteered to read paragraph 


\section{$10-28$}

Students beginning to write the $2^{\text {nd }}$ paragraph

Student \#17-listening attentively

Student \#27—volunteered an answer-beginning to write title

Both girls wrote a title

All 4 students put an " $\mathrm{X}$ " for indenting

$$
10: 45
$$

Students write topic sentence.

All 4 students listening to teacher's explanation

Student \#17 answered her question about how many reasons they should have

Student \#22 answered the question about how many indentions you should have

Student \#17 and Student \#14 paying attention

$10: 54$

Student \#27 beginning to write sentences

Student \#17 looking at his map and writing the sentences

Student \#27 continuing to write sentences

Student \#14-appearing inattentive

$10: 58$

The teacher told Student \#27 to go to another classroom and work (unable to shadow because he's in another classroom) 
Student \#17 has written half a page

Student \#22-continuing to write sentences

Student \#14 seemed stuck so I gave her ideas about how to write a sentence

11:04

Student \#17 continuing to write-looking at map

Student \#14 - now writing more sentences; looking at map and writing sentences

(student was helping another student write; I told her the student she was working with

had to do it on her own.)

$11: 10$

Student \#17 continuing to write sentences

Student \#14 continuing to write

Student \#27 returned and said he was done. 
Observation of Teacher at School B, 11-29-10

Preparation of $3^{\text {rd }}$ Writing Prompt

10:37 Student \#17 waiting patiently

Student \#14 reading the prompt

Student \#22 looking at prompt

The teacher mentioned that when they did this writing — it would be as if they were writing for the state.

Interesting —Each student had a copy of the prompt. She is going through the prompt and having them underline important words.

She told them that the reader must understand the students' reasons (she indicated to me that we weren't clear about the reasons last time.)

She went over why the students must have 3 reasons -1 would be below standard. She them underline the word "details" to support each of the their reasons

She asked the students, "What are we supposed to write about?" A student responded_-"A favorite day". She asked them, "What are some favorite days?" Student \#27 responded-“Summer Vacation" $10: 45$

All 4 students looking at the teacher's chart paper while they were brainstorming Teacher wrote the ideas on the board 
$10: 48$

All students paying attention

She spent some time getting them to understand they were writing about 1 day

She explained how the map correlated to the prompt. She mentioned in the first

paragraph that students needed to write some information about their event like who

was involved and where the event was.

The teacher modeled the Tree Map using her topic_-Thanksgiving 2010

$10: 58$

All 4 students began to complete the outline

11:02

Student \#14, Student \#22 and Student \#27 done with the outline; Student \#17 looks like he's done-thinking it over 
Observation of Teacher at School B 12-1-10

Interesting - In the teacher's class 2 double bubble maps about a tall tale character and native American folktale-similarities and differences

1. She had student re-read the prompt.

2. Reviewed what they did on Monday.

3 reasons - details

must be clear to the reader why you chose this day

3. Paper must have title—gave an example of topic sentence

fleshing out topic

Topic

*Reason Sentence \#1

--supporting detail

--supporting detail

--supporting detail

*Reason Sentence \#2

Asked them what detail sentences talk about—Student \#14 answered correctly;

Student \#27 responded correctly—second try

Applying the Tree Map to other purposes- 
Student asked about concluding sentence-Teacher asked what that sentence might do. A student said - to close the composition-teacher gave him a reward Had the students contribute signal words for reasons. Went over the title-then showed them how to indent the first paragraph.

$11: 03$

All students started to write the composition

11:08

Encouraged Student \#27 to keep writing. (I did)

$11: 15$

Student \#22-choosing favorite writing asst. in folder in preparation for the student interview. 
Observation of Teacher C-8-22-10-Presenting the first prompt

Teacher passed out a copy of the prompt for each student. She said she would read the prompt orally to them and they would follow along. She asked them if they had any questions. The teacher and I monitored them as they wrote.

At 10:10, many of them had written a paragraph. A few of them had started writing a second paragraph.

$80 \%$ of students wrote 1 paragraph. 
Observation of Teacher at School C, 9-30-10

Purpose of Lesson: Showing not Telling $10: 10$

All 4 listening to the teacher

All 4 reading the prompt with the teacher

Question: How do you start the first paragraph and address the prompt?

$10: 15$

Student \#14—working with another student; contributed ideas while the other student wrote

Student \#7-writing prompt on the white board

Student \#20 - contributed ideas "curious bear"- began writing paragraph

$10: 20$

Teacher gives students another prompt to share

Student \#20 — writing sentence addressing the prompt

Student \#7-writing response to prompt

Student \#14—working another student; orally read her paragraph; teacher asked students whether she addressed the prompt; they said yes $10: 20$

Student \#20-Wrote a sentence; erased it and started over Student \#7-Writing 2 sentences 
Student \#14-Writing 2 sentences

$10: 27$

Student \#20 — started right to work; still writing after she said to stop; wrote 2

sentences

Student \#7—-started right to work; she write 3 sentences; volunteered to read her work;

read it; teacher said "she owned it"

Student \#14 - started right to work; wrote a $1 / 4$ of a page

$10: 35$

All students listening to teacher as she read paragraphs to them.

Student \#20-Wrote sentences and volunteered them

Student \#7-not working with other students; working on her own

Student \#14-working with partner; partner wrote down sentences

$10: 40$

Student \#7_-discussed ideas with partner; the partner wrote her ideas

Student \#20-wrote sentences and volunteered to read it in class

Student \#14-discussed ideas with partner

$10: 43$

Student \#20-wrote at least 2 sentences

Student \#7-began adding sentences to those she had previously written-rose hand to share her stuff with the teacher 
Student \#14 - began second paragraph for first paragraph about a surprise limo ride 
Visitation of Teacher at School C

Second Writing Prompt

October 18,2010

I brought copies of the prompt which I gave to the students. The teacher read over the prompt with the students orally and answered any questions they had. Other than that, she offered no formal instruction in constructing a response. However, seven of her paper I gave them.

I had to replace one of the shadowed students because her mom did not want her to participate in the study.

9:50

Student \#14 - starting on $2^{\text {nd }}$ paragraph; good introduction Student \#7-still writing $1^{\text {st }}$ paragraph; looking at prompt 
Observation of Teacher at School C November 3

Subject: Students writing a summary

She had them read, as a class, parts of an articl

Student \#20 underlining some sentences in the article

$10: 27$

There were to share the main idea with a partner; Student \#14 volunteered the answer-it was right

Student \#20: writing article's name—other students listening

$10: 30$

Student \#7 raised her hand to answer question

4 students got out plan to underline details

All four students underlined details at the teacher's direction

$10: 33$

4 students continuing to underline

Student \#14 and Student \#15 paying attention

Student \#20 playing with pen

$10: 35$

all 4 students looking at the rubric

$10: 38$ 
Everybody but Student \#20 paying attention

$10: 40$

All 4 paying attention

Teacher had them writing summary in writing notebook

$10: 43$

Student \#14 consulting article as she's writing

She had students share some of their writing

Student \#14 raised her hand and read her work

Student \#7 raised her hand to read; she didn’t get a chance

to read because they had recess. 
Teacher at School C- $-3^{\text {rd }}$ Writing Prompt, 11-15-10

Teacher distributed the prompt to students and read it over with them. She had them begin working.

Interesting—students (not my interviewees) were asking questions like:

Does it have to take up the whole day?

Could a friend be included in the activity?

Can it be one family member?

Could we have more than 3 reasons?

9:05

Student \#7-thinking about what she's writing (asked how many paragraphs to write; I

I said one or 1 for description and a paragraph for each of the 3 reasons)

Student \#20, Student \#14 and Student \#15 beginning to write

9:10

All 4 writing

$9: 12$

Student $\# 14$ beginning $2^{\text {nd }}$ paragraph

$9: 15$

Student \#7 writing half a page

$9: 20$ 
All 4 students working steadily

All 4 have written at least half a page

Student \#14 writing $3^{\text {rd }}$ paragraph

Student \#20 writing $2^{\text {nd }}$ paragraph

$9: 25$

Student \#15 and Student \#7 done

Note: After the prompt was given, all 4 students were focused and wrote steadily until they finished. They didn't refer to the prompt while they were writing. 


\section{Appendix F}

The Writing Assessment Team

An area of the study that posed a concern was using a Writing Assessment Team to evaluate student work. The main problem was the lack of congruity among the evaluators' rubric scores especially with School B. When I designed the study, I decided to use three retired teachers I had known during my working career. One teacher had taught English at a middle school. The other two taught at the elementary school: one in fourth grade and the other in the primary grades. I chose these teachers because I believed they had demonstrated a high degree of professionalism and were quite able to adequately evaluate student work.

When they met with me to assess the first writing sample, I attempted to attain inter rater reliability by using two measures. First, I gave them a copy of compositions that resembled each of the rubric designations from one to four (one being the lowest score to four being the highest score). We discussed why these papers were evaluated the way they were. Second, I gave them two papers from each school to evaluate, for a total of six papers. I chose papers that ranged from an overall score of one to four using the rubric guidelines. Table 6.1 contains the combined rubric scores based on their assessments of the six papers.

1=Below Basic; 2=Basic; 3=Proficient; 4=Advanced 
Table 6.1

Rubric Scores for the Pilot Papers

\begin{tabular}{lcc}
\hline Evaluator $\mathrm{D}=3.14$ & Evaluator $\mathrm{E}=2.91$ & Evaluator $\mathrm{F}=3.0$ \\
\hline
\end{tabular}

Looking at the scores, one can see that there was not a great degree of difference that separated the three evaluators' assessments. So, after I reviewed the rubric with the evaluators, they began assessing the first set of papers. When I calculated the means for the rubric scores, Evaluator F's scores differed markedly from the other two evaluators when one looks at the scores for School B. One rubric point separated her score from that of Evaluator D which I considered significant.

1=Below Basic; $2=$ Basic; 3 =Proficient; $4=$ =Advanced

Table 6.2

Evaluators' Scores for Writing Prompt \#1

\begin{tabular}{lccc}
\hline & Evaluator D & Evaluator E & Evaluator F \\
\hline School A & 3.06 & 2.85 & 3.07 \\
School B & 3.08 & 2.48 & 2.02 \\
School C & 3.29 & 3.29 & 3.27 \\
\hline
\end{tabular}

In looking at the Evaluator F's score sheet, I noticed she gave the students' papers at School B many more 1's than the other two evaluators. I was unsure about how to address this problem. I thought the best way would be to review the rubric with the evaluators the next time we met and stress that, according to the rubric guidelines, the score of one should only be used if the student wrote no complete sentences and the composition had no sense of organization. So when the evaluators and I sat down in 
November, I reviewed the rubric designations with them and suggested that they follow the rubric's guidelines regarding when a score of 1 should be used. When I calculated the results of the second writing prompt, I discovered the pattern had continued with Evaluator F's assessment of the students' compositions from School B. Also, there was a least one rubric point difference between her rubric score of School C and that of Evaluator D. The results of these assessments can be found in Table 6.3 below. 1=Below Basic; 2-Basic; 3=Proficient; 4=Advanced

Table 6.3

Evaluators' Scores for Writing Prompt \#2

\begin{tabular}{lccc}
\hline & Evaluator D & Evaluator E & Evaluator F \\
\hline School A & 2.71 & 2.56 & 2.48 \\
School B & 2.79 & 2.27 & 1.48 \\
School C & 3.08 & 2.97 & 2.37 \\
\hline
\end{tabular}

However, this situation changed with the third writing prompt. Evaluator F gave the highest scores for Schools B and C and tied with Evaluator E for the higher score for School A. The results can be found below in Table 6.4.

1=Below Basic; 2=Basic; 3=Proficient; 4=Advanced 
Table 6.4

Evaluators' Scores for Writing Prompt \#3

\begin{tabular}{lccc}
\hline & Evaluator D & Evaluator E & Evaluator F \\
\hline School A & 2.25 & 2.3 & 2.3 \\
School B & 2.36 & 2.17 & 2.65 \\
School C & 2.96 & 3.07 & 3.09 \\
\hline
\end{tabular}

In talking with Evaluator F, I learned why her assessments for the third writing sample were higher than her scores for the second writing sample, especially for School B. She told me she believed these papers were better written because their organization had improved compared to the second writing sample.

\section{Discussion}

These tables illustrated the problem of the lack of congruity among the evaluators' assessments. I believed that if I reviewed with the evaluators what the rubric score guideline of 1 constituted in assessing a student paper that Evaluator $\mathrm{F}$ would use it less frequently especially with School B. That did not occur with the second writing prompt. One factor that might have caused Evaluator $\mathrm{F}$ to give the papers at School B a lower evaluation than the other two evaluators is the fact that this teacher had taught English at the middle school for much of her career. Thus, her expectations may not have been as realistic as the two teachers who had worked with elementary school children during their professional careers. 
On the other hand, having these evaluators assess student work did have some advantages. Their participation constituted a degree of objectivity in assessing the students' papers. Because they had no involvement with the student participants, their assessments would not be colored by knowing the students or their work. Thus, their assessments would be more valuable because their scores were only derived from the quality of the students' compositions.

Another advantage was having three, rather than a lower number, of assessors. In that way, the scores of Evaluators D and E evened out those of Evaluator F especially for School B. Also, it is interesting to note that the three evaluators' scores appeared to correspond more closely for Schools A and C for writing prompts 2 and 3.

Finally, having the team of evaluators assess the student papers allowed me to understand why they judged the papers the way they did. Their opinions provided an important perspective by stating why students didn't do as well as they might have on their compositions because they failed to address the prompt. If I were a principal at a school, I would use this knowledge to help my teachers instruct their students in answering a writing prompt effectively. This skill is very important for students to know especially when they complete essays for college or graduate school admission. 